\title{
Multi-year GNSS monitoring of atmospheric IWV over Central and South America for climate studies
}

\author{
Clara Eugenia Bianchi ${ }^{1,2}$, Luciano Pedro Oscar Mendoza ${ }^{1,2}$, Laura Isabel Fernández ${ }^{1,2}$, María Paula Natali ${ }^{1,2}$, \\ Amalia Margarita Meza ${ }^{1,2}$, and Juan Francisco Moirano ${ }^{1}$ \\ ${ }^{1}$ Laboratorio de Meteorología espacial, Atmósfera terrestre, Geodesia, Geodinámica, diseño de Instrumental y Astrometría \\ (MAGGIA), Facultad de Ciencias Astronómicas y Geofísicas (FCAG), Universidad Nacional de La Plata (UNLP), \\ Paseo del Bosque s/n, B1900FWA, La Plata, Argentina \\ ${ }^{2}$ Consejo Nacional de Investigaciones Científicas y Técnicas (CONICET), La Plata, Argentina
}

Correspondence to: Luciano Pedro Oscar Mendoza (lmendoza@fcaglp.unlp.edu.ar)

Received: 2 March 2016 - Revised: 10 June 2016 - Accepted: 22 June 2016 - Published: 20 July 2016

\begin{abstract}
Atmospheric water vapour has been acknowledged as an essential climate variable. Weather prediction and hazard assessment systems benefit from real-time observations, whereas long-term records contribute to climate studies. Nowadays, ground-based global navigation satellite system (GNSS) products have become widely employed, complementing satellite observations over the oceans. Although the past decade has seen a significant development of the GNSS infrastructure in Central and South America, its potential for atmospheric water vapour monitoring has not been fully exploited. With this in mind, we have performed a regional, 7-year-long and homogeneous analysis, comprising 136 GNSS tracking stations, obtaining high-rate and continuous observations of column-integrated water vapour and troposphere zenith total delay. As a preliminary application for this data set, we have estimated local water vapour trends, their significance, and their relation with specific climate regimes. We have found evidence of drying at temperate regions in South America, at a rate of about 2\% per decade, while a slow moistening of the troposphere over tropical regions is also weakly suggested by our results. Furthermore, we have assessed the regional performance of the empirical model GPT $2 \mathrm{w}$ to blindly estimate troposphere delays. The model reproduces the observed mean delays fairly well, including their annual and semi-annual variations. Nevertheless, a long-term evaluation has shown systematical biases, up to $20 \mathrm{~mm}$, probably inherited from the underlying atmospheric reanalysis. Additionally, the complete data set has been made openly available as supplementary material.
\end{abstract}

\section{Introduction}

Atmospheric water vapour plays a dominant role in the radiative balance and the hydrological cycle (Turco, 1992). It constitutes a prominent greenhouse gas controlling the heat budget of the planet (Philipona et al., 2005). Although the water vapour is limited almost exclusively to the troposphere and most of the global-mean quantity is confined to the first $2 \mathrm{~km}$ above the surface (Ross and Elliott, 1996), it has a highly variable and complex distribution that evolves on timescales ranging from hours to a day (Salby, 1992). In consequence, accurate, high-rate, global, and continuous water vapour measurements are essential for weather prediction and natural hazards assessment, as well as for long-term studies of climate change. In fact, the increase in specific humidity shown by global analysis constitutes one more piece of evidence for steady global warming (Hartmann et al., 2013).

While nowadays many instruments and techniques provide profiles or column-integrated water vapour (IWV) measurements with diverse degrees of accuracy, continuity, and spatial and temporal resolutions (e.g. radiosondes and ground- and satellite-based infrared or microwave radiometers), global navigation satellite system (GNSS)based column-integrated water vapour products have become widely used. This technique, since its first devising (Bevis et al., 1992, 1994; Duan et al., 1996), is now well established and mature. It is able to provide continuous, all-weather and highly accurate measurements at low cost. It is even possible to obtain observations at near-real time (e.g. Ware et al., 2000; Karabatić et al., 2011; Li et al., 2014), capable to be ingested by weather now-casting analysis (de Haan et al., 2004; 
de Haan et al., 2009). Also important for long-term studies, GNSS-based observations are not affected by the stability issues that could arise when working with radiosondes profiles due to changes in instrumentation, calibration, or analysis methods (Zhai and Eskridge, 1996).

Based on operational troposphere delay time series, provided by the International GNSS Service (IGS, Dow et al., 2009), several global-scale analysis of atmospheric water vapour content have been published. For example, Wang et al. (2007) employed actual observations of surface pressure and air temperature records to retrieve, from those observed delays, column IWV. Due to the lack of in situ weather observations at most of the IGS tracking sites they devised a correct, although involved, procedure in order to obtain atmospheric pressures at the GNSS instruments location. Aiming to overcome the same issue, Heise et al. (2009) analysed the utilisation of synthetic pressure observations from numerical weather models (NWMs), assessing the impact of this approach on the uncertainty of the water vapour estimates. On the other hand, Vey et al. (2009) were able to retrieve water vapour time series from a homogeneous reprocessing of GNSS observations, later employing these independent products to perform a global and long-term validation of a NWM (Vey et al., 2010). Jin et al. (2007) studied the seasonal variability in GPS-derived products and their trends, while Steigenberger et al. (2007) compared the longterm trends estimated with GPS and very-long-baseline interferometry (VLBI) techniques, although in both works the analysis were restricted to time series of troposphere delay. Also, a general good agreement between ocean-based satellite and GNSS-derived column IWV observations has been established (Mears et al., 2010).

None of the mentioned long-term and global analysis had a particularly good coverage in Central and South America. Moreover, previous regional analysis of GNSS-derived water vapour in South America had narrow spatial and temporal coverage, employed GPS-only observations, and were focused on the validation of the methodology by comparison against radiosondes measurements (Sapucci et al., 2007), or radiosondes and satellite-based observations (Fernández et al., 2010). Another regional inter-technique comparison was performed by Calori et al. (2015), using GPS-only observations, comprising about 30 sites, and spanning 2 years. Recently, a 1-year-long experiment employing an episodic but highly dense meteorological GNSS network in Amazonia studied water vapour-convection interactions in the tropics (Adams et al., 2015). On the other hand, a large and welldistributed GNSS network covering Central America and the Caribbean has been producing, since 2012, column IWV at near-real time (Feaux et al., 2012).

Here we present an independent, homogeneously computed, dense, and almost continent-wide estimation of atmospheric water vapour content from GNSS observations in Central, South America, and the Caribbean. Although the data only span 7 years, we believe they could constitute a valuable contribution to regional and global climate studies. For this reason, we have made the complete data collection openly available as supplementary material (Bianchi et al., 2016). As a preliminary application for these products we have analysed the regional performance of the recently released troposphere model GPT2w (Böhm et al., 2015). In addition, we have computed regional and local trends of water vapour content, together with realistic uncertainties, studying the correlation between these parameters and several climate regimes. We describe in detail the methodology employed in the overall analysis and the results of a comparison performed between our estimates and several IGS troposphere products. Also, we have made a comprehensive account of the procedure employed to work out the lack of in situ atmospheric pressure measurements at most of the processed GNSS sites.

Moreover, given the spatial distribution of the GNSS sites and the sampling rate and continuity of the estimated water vapour time series, these data could also be employed in other multiple research areas - for example, the assessment of global NWMs, the analysis of daily and sub-daily water vapour variability, the calibration of satellite-based radiometer (on land) measurements, or studies of mesoscale convective systems.

\section{Data and methods}

\subsection{GNSS observations}

In this study GNSS observations spanning 7 years, between January 2007 and December 2013, were analysed. The selected tracking stations have a near-continentwide distribution, from southern California to Tierra del Fuego, and belong to International GNSS Service Network (IGS, http://www.igs.org/), Systéme d'Observation du Niveau des Eaux Littorales (SONEL, http://www.sonel.org/ -GPS-.html), Rede Brasileira de Monitoramento Contínuo dos Sistemas GNSS (RBMC, Brazil, http://www.ibge.gov. br), and Red Argentina de Monitoreo Satelital Continuo (RAMSAC, Argentina, www.ign.gob.ar). In total, our analysis involved 136 stations, including a few reference stations in Antarctica and islands in the Atlantic and Pacific oceans.

The particular selection of tracking stations was mainly determined by two reasons. First, we included as many regional IGS sites as possible to assure a good alignment of the daily solutions to the IGS08 terrestrial reference frame (Rebischung et al., 2012). Second, and also important for the present study, we included many non-IGS regional stations. Some of them were already incorporated by several analysis centres (ACs) into their contribution to the IGS second reprocessing campaign (repro2; Rebischung, 2015). In addition, the final station selection was also constrained by the actual availability of the raw observations in open-access repositories. This condition, aside from the GNSS observations, also 
Table 1. The IGS products employed for the zenith total delay (ZTD) estimate evaluation.

\begin{tabular}{cccrrrr}
\hline Solution & $\begin{array}{c}\text { Analysis } \\
\text { centre }\end{array}$ & $\begin{array}{c}\text { Mapping } \\
\text { function }\end{array}$ & $\begin{array}{c}\text { Elevation cutoff } \\
\text { angle [deg] }\end{array}$ & $\begin{array}{c}\text { Sampling } \\
\text { rate [s] }\end{array}$ & Remarks & $\begin{array}{c}\text { Sites in common } \\
\text { with this work }\end{array}$ \\
\hline operational & JPL & NIELL (Niell, 1996) & 7 & 300 & until 16 April 2011 & 45 \\
operational & USNO & WET GMF (Böhm et al., 2006a) & 7 & 300 & since 17 April 2011 & 45 \\
repro2 co2 & CODE & WET VMF (Böhm et al., 2006b) & 3 & 7200 & & 42 \\
repro2 jp2 & JPL & GPT2 (Lagler et al., 2013) & 7 & 300 & no gradients \\
\hline
\end{tabular}

extends to all other employed data. It ensures the complete or partial reproducibility of the present work.

\subsection{GNSS data analysis}

The observations were processed with the Bernese GNSS Software version 5.2 (Dach et al., 2015), at a doubledifference level, and models recommended by the International Earth Rotation and Reference Systems Service (IERS) were used (Petit and Luzum, 2010). Therefore, ocean tidal loading corrections, according to Letellier (2004), atmospheric tidal loading displacements, provided by van Dam and Ray (2010), and absolute phase-centre corrections for satellites and receivers, as issued by the IGS (file IGS08.atx), were applied. First-order ionospheric delays were eliminated by means of the ionosphere-free linear combination, and higher-order terms were modelled according to Fritsche et al. (2005).

In addition, troposphere zenith total delays (ZTDs) were modelled as $30 \mathrm{~min}$ linear piecewise estimates, applying the wet term of the Vienna Mapping Function 1 (VMF1; Böhm et al., 2006b), together with daily gradients according to Chen and Herring (1997). Consistent a priori values for the zenith hydrostatic delays (ZHDs) were introduced, from a spatial and temporal interpolation of the 6-hourly fields of a NWM. These delays are readily provided by the Vienna University of Technology (TUW), and they are derived from the most recent NWM (Dee et al., 2011) produced by the European Centre for Medium-Range Weather Forecasts (ECMWF). A low-elevation cutoff angle of $3^{\circ}$ was consistently used during the analysis of the whole data set.

To assure a homogeneous set of GPS + GLONASS precise orbits and clocks, and consistent Earth orientation parameters (EOPs), reprocessed products computed by the Center for Orbit Determination in Europe (CODE) were used. In particular, we made use of the co 2 orbits, clocks, and EOPs generated, as part of CODE's repro2 re-analysis, from 3-day long-arc solutions (Steigenberger et al., 2014). Additionally, operational ionospheric maps and differential code biases (DCBs), also provided by CODE, were employed. As mentioned, the IGS08 terrestrial reference frame was introduced by means of constraints on coordinates of selected IGS tracking sites.

\subsection{Comparison between ZTD time series}

In order to quantify the consistency of our ZTD estimates, and particularly to look for the presence of any long-term bias, we performed a site-by-site comparison with three different data sets produced by IGS ACs (Table 1). These time series, besides the operational troposphere products computed by the Jet Propulsion Laboratory (JPL) and the US Naval Observatory (USNO) (see Byun and Bar-Sever, 2009), include the homogeneous ZTD time series computed by CODE and JPL for the repro2 re-analysis (co2 and jp2 solutions, respectively).

For each site, the total mean difference between solutions and the corresponding root mean squares (RMSs) were computed. Before differencing, all time series were screened and ZTD estimates with an standard deviation above a given tolerance were masked out $\left(\sigma_{\mathrm{ZTD}}>4 \mathrm{~mm}\right)$. Also, the IGS operational data were cleansed of unrealistic estimates present in some (old) SINEX files (issue already reported by Böhm et al., 2015). In total, we removed about $3 \%$ of all the ZTD records available for these comparisons.

In addition, the co2 and jp2 solutions were also intercompared. The resulting site-by-site and total mean differences were used as an indicator of the expected consistency between estimates from two homogeneous but independent analysis.

\subsection{Comparison with modelled troposphere delays}

We performed a comparison between the ZTD estimates from our GNSS analysis and the values derived from the troposphere empirical model GPT2w (Böhm et al., 2015). This model has many applications, not only in real-time navigation but also when highly precise determinations of slant troposphere delays are required but mapping function coefficients from NWMs are not readily available. Furthermore, GPT2 $w$ can also provide the weighted mean temperature $\left(T_{\mathrm{m}}\right)$ above the site, a quantity required to retrieve IWV from observed ZTD.

In order to assess the long-term performance of the troposphere delays derived from the GPT2w model, in Central and South America, we computed the daily and total mean difference, as well as the corresponding RMS, between ZTDs derived from GPT2w and GNSS observations. This analysis was performed over each one of the 136 GNSS sites in- 
cluded in our processing. For this comparison annual and semi-annual periodic terms were included in the computation of the GPT2w's derived parameters. Following the methodology applied by Böhm et al. (2015), for their 1-year-long comparison against IGS operational products, modelled ZHDs and zenith wet delays (ZWDs) were computed according to Davis et al. (1985) and Askne and Nordius (1987), respectively.

\subsection{Computation of IWV time series}

In order to retrieve IWV estimates from our observed ZTD time series we applied a methodology similar to the one described by Wang et al. (2007). In practice, ZHDs were computed according to Davis et al. (1985) but employing observed atmospheric pressures and site heights taken from the daily GNSS solutions. Then, the computed ZHDs were subtracted from the observed ZTDs to retrieve the wet terms (i.e. ZWDs). Finally, the ZWDs were scaled by a proportionality constant, as described by Askne and Nordius (1987), to obtain IWV estimates every $30 \mathrm{~min}$.

Combining the expressions given by Davis et al. (1985) and Askne and Nordius (1987) the IWV can be estimated by

$\mathrm{IWV}=10^{6} \frac{\mathrm{ZTD}-\frac{2.2768 P}{1-2.8 \times 10^{-7} h-0.00266 \cos 2 \varphi}}{\rho R_{\mathrm{v}}\left(\frac{k_{3}}{T_{\mathrm{m}}}+k_{2}^{\prime}\right)}$,

where $P$ is the atmospheric pressure at the GNSS benchmark, $h$ is the corresponding geodetic height, $\varphi$ is its corresponding latitude, $R_{\mathrm{V}}$ is the specific gas constant for water vapour $\left(461.5181 \mathrm{~kg} \mathrm{~K}^{-1}\right), \rho$ is the density of liquid water $\left(1000 \mathrm{~kg} \mathrm{~m}^{-3}\right), T_{\mathrm{m}}$ is the tropospheric weighted mean temperature above the GNSS site, $k_{3}$ is a refractivity constant $\left(3739 \mathrm{~K}^{2} \mathrm{~Pa}^{-1}\right)$, and $k_{2}^{\prime}$ is a derived constant $\left(0.221 \mathrm{~K} \mathrm{~Pa}^{-1}\right.$; see Bevis et al., 1994). In particular, if the height is introduced in metres $(\mathrm{m})$, the pressure in hectopascals $(\mathrm{hPa})$, the zenith total delay in millimetres $(\mathrm{mm})$, and the weighted mean temperature in kelvin $(\mathrm{K})$, then the integrated water vapour computed with Eq. (1) results in kilograms per square metre $\left(\mathrm{kg} \mathrm{m}^{-2}\right)$ of water vapour present in a vertical atmospheric column.

As mentioned above, observations of atmospheric pressure at the GNSS sites were required. Considering that in situ observations were only available for 12 of the processed GNSS sites, we followed the strategy employed by Wang et al. (2007) to solve the same issue. That is, the weighted averages of pressure observations from synoptic stations located at less than $50 \mathrm{~km}$ from each GNSS site were computed, accounting for the effect of the height differences (see Appendix A) and weighting each measurement according to the inverse of its distance to the corresponding GNSS site. The averaged pressures were interpolated every $30 \mathrm{~min}$ if required, but only within data gaps shorter than $8 \mathrm{~h}$. Time series of atmospheric pressure, at the level of the GNSS benchmarks, were obtained for 112 of the processed sites. Finally, in order to quantify the error involved in the overall process, a comparison was performed on those IGS sites where in situ measurements were actually available, resulting in a mean RMS of $0.9 \mathrm{hPa}$.

In this work we employed atmospheric pressure data sets provided by the University of Wyoming (UW, global surface observations available at http://weather.uwyo.edu/), by the National Oceanic and Atmospheric Administration (NOAA, ISD-lite product available at ftp://ftp.ncdc.noaa. gov/pub/data/noaa/isd-lite/), and by the IGS (RINEX m-files, available at ftp://cddis.gsfc.nasa.gov/gps/data/daily/ and alternative repositories). Before any computation all available pressure records were cleansed of unrealistic values (see Appendix A).

In essence, the three main error sources for the IWV estimate are the uncertainties in the surface pressure, in the observed ZTD, and in the weighted mean temperature above the GNSS site (Bevis et al., 1994). Taking the partial derivatives of IWV with respect to $P$, ZTD, and $T_{\mathrm{m}}$, and assuming no cross-correlations, the formal variance for the estimates can be approximated as

$\sigma_{\mathrm{IWV}}^{2} \approx\left(\frac{\partial \mathrm{IWV}}{\partial P}\right)^{2} \sigma_{\mathrm{P}}^{2}+\left(\frac{\partial \mathrm{IWV}}{\partial \mathrm{ZTD}}\right)^{2} \sigma_{\mathrm{ZTD}}^{2}+\left(\frac{\partial \mathrm{IWV}}{\partial T_{\mathrm{m}}}\right)^{2} \sigma_{T_{\mathrm{m}}}^{2}$,

and then the following numerical relation is found when typical values for the parameters are introduced:

$\sigma_{\mathrm{IWV}}^{2} \approx 0.13 \sigma_{\mathrm{P}}^{2}+0.024 \sigma_{\mathrm{ZTD}}^{2}+0.012 \sigma_{T_{\mathrm{m}}}^{2}$.

In this study, we derived $T_{\mathrm{m}}$ from the 6-hourly model levels of the ERA-Interim NWM (Dee et al., 2011), strictly following the methodology described by Wang et al. (2016a). That is, for each GNSS site the $T_{\mathrm{m}}$ was computed at the nearest four grid nodes of the NWM, integrating from the upper model level down to the geopotential height of the GNSS benchmark, and then interpolating linearly at the site's location and at the observation epoch (the ZTDs were estimated every $30 \mathrm{~min}$ ). If required, extrapolated profiles of air temperature and relative humidity every $50 \mathrm{~m}$ were introduced at those sites located below the lower model level. From a 13year comparison of this methodology against $T_{\mathrm{m}}$ values derived from radiosonde profiles, at 20 GNSS sites, Wang et al. (2016a) found a mean RMS value of $0.5 \%\left(\sigma_{T_{\mathrm{m}}} \approx 1.5 \mathrm{~K}\right)$. In addition, we restricted the analysis to ZTD estimates with a standard deviation $\sigma_{\mathrm{ZTD}} \leq 4 \mathrm{~mm}$. Also, as mentioned above, we estimated the uncertainty for the averaged pressures as $\sigma_{\mathrm{P}} \approx 1 \mathrm{hPa}$. Then, the formal standard deviation for the IWV estimates was approximated as $\sigma_{\text {IWV }} \approx 1 \mathrm{~kg} \mathrm{~m}^{-2}$ of water vapour present in a vertical atmospheric column, equivalent to $1 \mathrm{~mm}$ of liquid water column. Finally, our IWV estimates were compared with several co-located radiosonde observations, also provided by UW (upper-air data set, http: //weather.uwyo.edu/). 


\subsection{Analysis of the IWV estimates}

In order to detect possible trends in the IWV time series, we applied a methodology similar to the one described by Nilsson and Elgered (2008). Essentially, we estimated a mean, a linear trend, and periodic annual, semi-annual, and diurnal terms to the observed water vapour content at each site. Thus, the functions adjusted to the IWV time series are

$$
\begin{aligned}
f(t) & =a_{0}+a_{1} \frac{t-t_{0}}{3652.5} \\
& +a_{2} \sin \left(\frac{2 \pi t}{365.25}\right)+a_{3} \cos \left(\frac{2 \pi t}{365.25}\right) \\
& +a_{4} \sin \left(\frac{4 \pi t}{365.25}\right)+a_{5} \cos \left(\frac{4 \pi t}{365.25}\right) \\
& +a_{6} \sin (2 \pi t)+a_{7} \cos (2 \pi t),
\end{aligned}
$$

where we assumed, a priori, independent observations (white noise). Here $t$ is expected in modified Julian days, whereas $t_{0}$ represents the mean epoch of the observations. For time series spanning less than 5 (mostly continuous) years the second term at the right of Eq. (4) was omitted (i.e. no trends were computed).

In Eq. (4), the mean and decadal trend parameters are $a_{0}$ and $a_{1}$, respectively. Also, the annual, semi-annual, and diurnal amplitudes are represented in Eq. (4) by the pairs $\left(a_{2}, a_{3}\right)$, $\left(a_{4}, a_{5}\right)$, and $\left(a_{6}, a_{7}\right)$, respectively. While Nilsson and Elgered (2008) only included periodic annual and semi-annual parameters, we also added daily terms. This takes into account strong diurnal signals present in some of the analysed time series (particularly in the tropics).

For each site, the autocovariance of the residuals of the adjustment, as a function of the time, was computed and modelled by

$\operatorname{Cov}\left(t_{1}, t_{2}\right)=k_{1} e^{-\left|t_{1}-t_{2}\right| / T_{1}}+k_{2} e^{-\left|t_{1}-t_{2}\right| / T_{2}}$.

With these models, realistic variance-covariance matrices for the observations, including significant temporal correlations that extend several days, were constructed. Here a maximum temporal lag $\left|t_{1}-t_{2}\right|$ of 2 weeks was considered. Then, following Nilsson and Elgered (2008), the variance-covariance matrices of the estimated parameters were recomputed by the formal introduction of the modelled temporal correlations. Taking into account these significant temporal correlations present in the data, realistic uncertainties for the estimated parameters were obtained. If these correlations are not considered, the uncertainties for the trends are underestimated, on average, by a factor of 10 .

\section{Results and discussion}

\subsection{GNSS processing evaluation}

In general, all the compared ZTD solutions show good agreement, with long-term mean inter-biases lower than half a mil- limetre (Fig. 1). The site-by-site comparison between our estimates and the operational IGS products reveals the largest systematic biases, up to $5 \mathrm{~mm}$, both in excess and in deficit (Fig. 1a). In this case, the discrepancies are probably related to the use of a specific mapping function (i.e. Niell, 1996). In contrast, these biases are non-existent, or they are greatly reduced, when our products are compared with both CODE and JPL reprocessing results (co2 and jp2 solutions, Fig. 1b and $\mathrm{c}$, respectively).

The co2 and jp2 solutions show the best agreement, although some systematic bias exists in central Chile and $\mathrm{Ar}$ gentina (Fig. 1d). In this case our results fully agree with CODE's estimates, showing the same differences with respect to JPL's results. The exact reason for this small bias is not investigated here, but, given the known high correlation between height and troposphere delay estimates, it is probably related to the alternative approaches employed by each $\mathrm{AC}$ regarding atmospheric loading. Indeed, van Dam et al. (2010) found that, owing to the high topographic variability, significant estimated height errors, between 2 and $4 \mathrm{~mm}$, could be expected for sites in that region. Fundamentally, it depends on the spatial resolution of the loading model employed and the accuracy of its underlying topographic grid.

In total, the quality of our ZTD estimates is on par with both IGS reprocessing analyses and it surpasses the consistency of the operational products. As expected, our results agree more closely with CODE's estimates, thanks to the use of similar processing strategies, models, and software, but also because we employed co2 reprocessed orbits and EOPs. Finally, we found no reason not to extend this confidence to the ZTD estimates of all the remaining GNSS sites processed. Therefore, all further inferences and discussions are based on the complete set of 136 ZTD time series resulting from our GNSS analysis.

\subsection{Troposphere model assessment}

The performance of the GPT2w model in Central and South America, for the computation of ZTD parameters, clearly results within the ranges reported by Böhm et al. (2015) for both the long-term mean values and their corresponding dispersion (Fig. 2). In particular, the model does an excellent job reproducing local ZTD annual and semi-annual signals, with no significant residual terms at (almost) any site. However, some systematic behaviours, spatially or temporally correlated, could be observed.

On average the modelled mean delays present no bias with respect to the observed ones. However, the modelled ZTDs seems to be systematically underestimated, by up to $20 \mathrm{~mm}$, at sites in wet regions, mostly located between the northern and southern tropical circles (Fig. 2a). Böhm et al. found a similar bias in Central America and the Caribbean region, but it was disregarded due to the very short span of the local data employed in their analysis (about 4 months). According to our results the bias exists and it extends deeply to the 

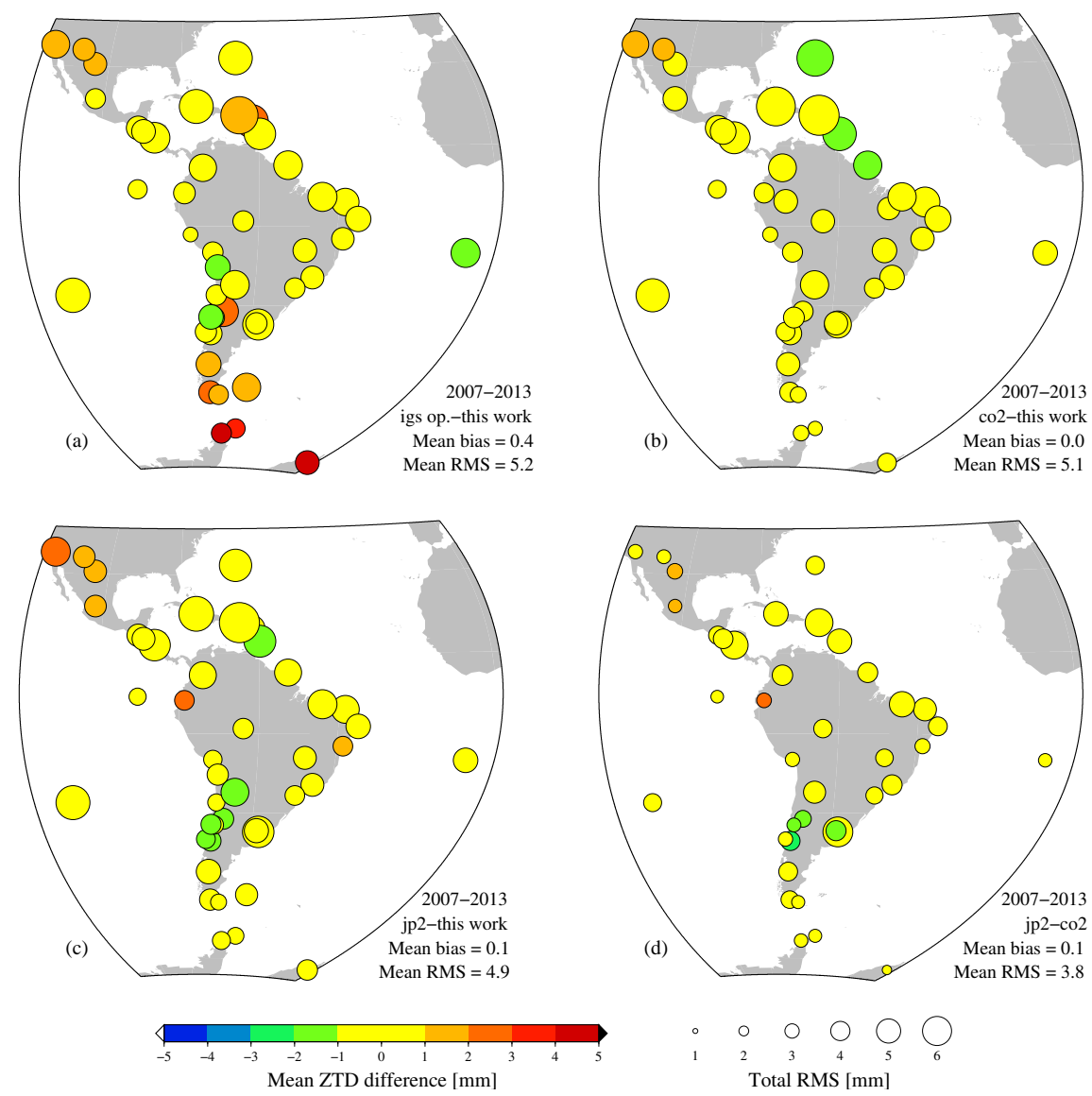

Figure 1. Long-term comparison of estimated troposphere zenith total delays. (a) IGS operational products with respect to this work. (b) The repro2 co2 solutions (CODE) with respect to this work. (c) The repro2 jp2 solutions (JPL) with respect to this work. (a) The repro2 jp2 solutions (JPL) with respect to repro2 co2 solutions (CODE). The mean biases and mean RMS are in millimetres.

(a)

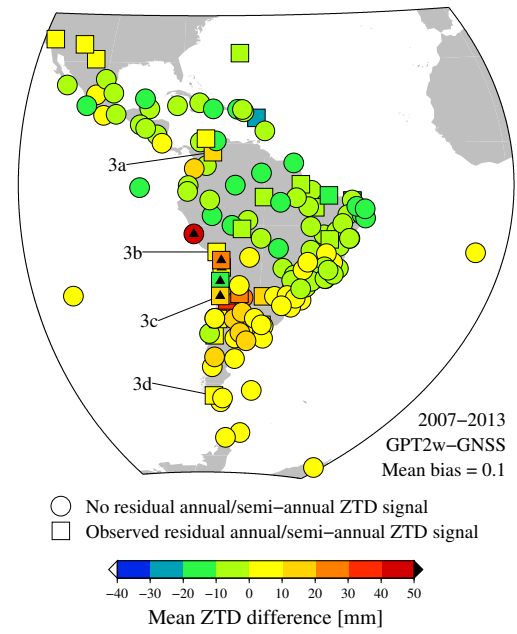

(b)

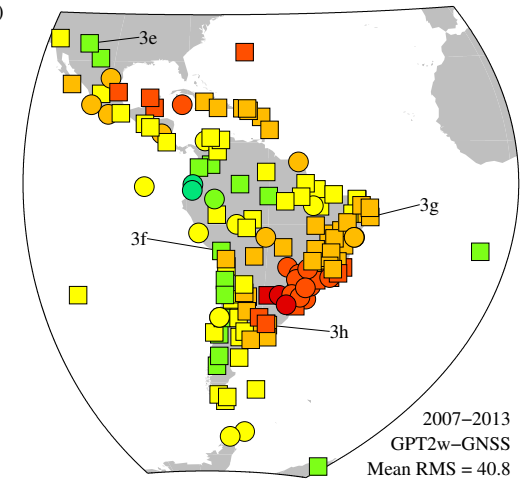

No predominantly annual/semi-annual signal on (daily) RMS Predominantly annual/semi-annual signal on (daily) RMS

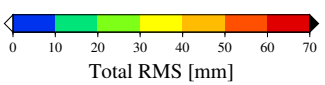

Figure 2. Regional assessment of the GPT2w blind model. (a) Mean differences between modelled (GPT2w) and observed (GNSS) ZTDs. The black triangles indicate those sites where the orthometric height difference, between the nearest GPT2w topographic grid nodes and the corresponding GNSS benchmark, exceeds $2500 \mathrm{~m}$. The sites plotted in Fig. 3a, b, c, and d are also indicated here. (b) Total RMS of the corresponding differences. The sites plotted in Fig. $3 \mathrm{e}, \mathrm{f}, \mathrm{g}$, and $\mathrm{h}$ are also indicated here. 

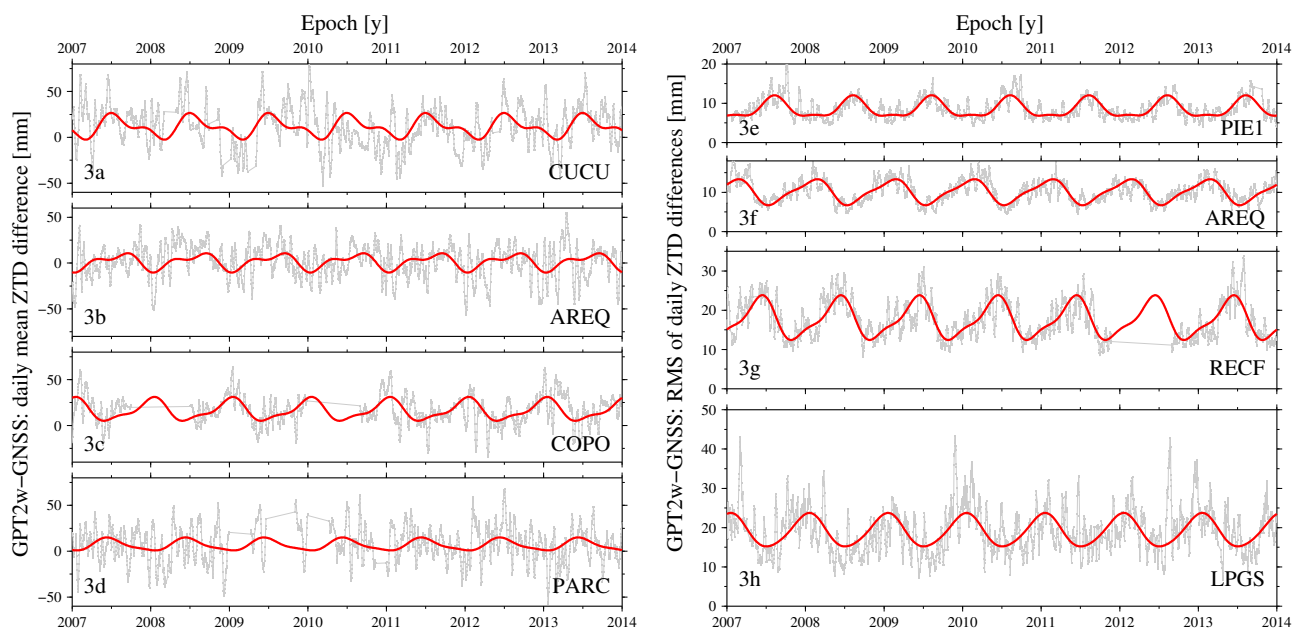

Figure 3. Left panels: time series of daily mean differences (grey dots), between modelled (GPT2w) and observed (GNSS) troposphere delays, showing residual annual and semi-annual signals (solid red lines). Right panels: time series of daily RMS (grey dots) showing residual annual and semi-annual signals (solid red lines). The location of each site is indicated in Fig. 2. The time series plotted were smoothed (10-day-width moving average).

south, into South America. However, modelled values at arid and temperate regions in southern South America result, on average, in overestimations of up to $20 \mathrm{~mm}$. Biases of similar magnitude were found by Böhm et al. for sites in northern North America (underestimated delays) and Europe (overestimated delays). At a few sites, particularly in northern Chile and Peru, the mean ZTD bias also presents variations that clearly follow an annual and semi-annual period, with amplitudes of about $25 \mathrm{~mm}$ (e.g. Fig. 3a, b, c, and d; sites indicated in Fig. 2a). Nevertheless, as already mentioned, modelled values at most of the sites are not affected by these residual signals.

In addition, some of the systematic biases observed in South America seem to be related to the insufficient resolution of the GPT2w's underlying topographic model to accurately reproduce the highly variable topography near the Andes (Fig. 2a, black triangles). Indeed, the GPT2w model extrapolates several parameters from its reference surface to the height of the point of interest. Although the computation of the modelled ZHDs only requires extrapolated air pressures, the computation of the ZWDs additionally requires extrapolated air temperatures and water vapour partial pressures (which strongly depends on the modelled specific humidity at the reference surface). In particular, downward extrapolations over several thousands metres could lead to an overestimation of the modelled ZWD by several centimetres. As an extreme example, the model systematically overestimated the ZTD at the site CALL (El Callao, Peru) by almost $50 \mathrm{~mm}$ (Fig. 2a, red circle with a superimposed black triangle). In this case the orthometric height of the corresponding GNSS benchmark is $5 \mathrm{~m}$, while the four surrounding grid nodes have orthometric heights of $13,507,1711$, and $3761 \mathrm{~m}$, respectively.
The total RMS of the ZTD differences also results within the ranges reported by Böhm et al. (2015), with a regional mean value of $\sim 41 \mathrm{~mm}$ (Fig. $2 \mathrm{~b}$ ). In contrast with the behaviour shown by the daily mean ZTD differences, the respective daily RMS values do contain predominantly annual and semi-annual signals on most of the sites analysed (e.g. Fig. 3e, f, g, and h; sites indicated in Fig. 2b). At the remaining sites annual and semi-annual signals are probably also present, but they are not evident by the presence of additional components with shorter periods but significant amplitudes. Here the site-by-site comparisons also reveal some spatial correlation, with minimum RMS values along western South America and maximum values on sites located in southern Brazil and central-eastern Argentina. As suggested by Böhm et al., the future addition of diurnal and semi-diurnal amplitudes into the model would surely help to mitigate the observed dispersion.

It is worth noting that the present analysis could not discriminate the precise source of the observed systematic behaviour, although the mean biases are probably inherited from the underlying NWM, in this case ERA-Interim (Dee et al., 2011). In fact, significant discrepancies in the water vapour data sets from ERA-Interim and two other thirdgeneration reanalysis had been determined, particularly in South America, and are attributed to the lack of sufficient radiosondes measurements (Wang et al., 2016b). Indeed, Wang et al. report differences amounting up to $2.5 \mathrm{~kg} \mathrm{~m}^{-2}$ on lands, equivalent to about $15 \mathrm{~mm}$ of troposphere zenith total delay. In any case, given an application requiring the synthetic slant delays provided by GPT $2 \mathrm{w}$, it might be worthwhile introducing local or regional correction biases. Nevertheless, the possible benefits of this approach should be assessed in more detail. 

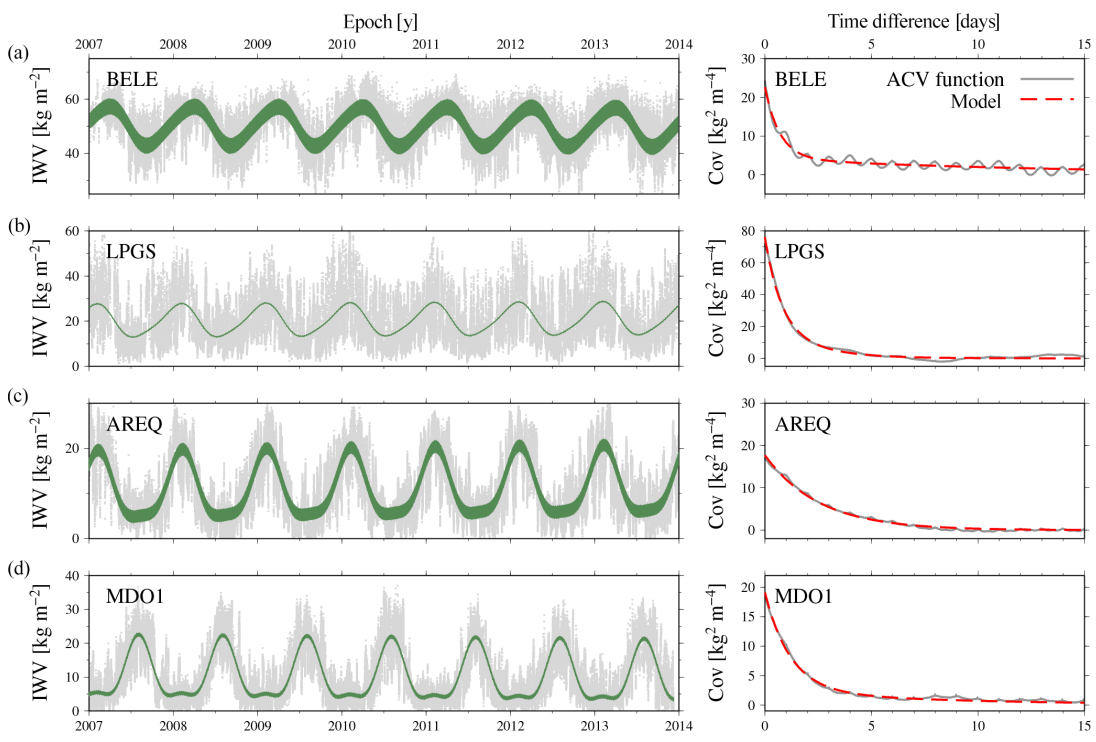

Figure 4. Left panels: representative examples of observed IWV time series (grey dots) and models (solid green lines). Right panels: autocovariance (ACV) function of the residual IWV time series (solid grey lines) and covariance modelling (dashed red lines).

\subsection{IWV retrieval and analysis}

In total, observed IWV time series for 110 GNSS sites, spanning at least 1 year, were obtained. No discontinuities were observed at any site due to the involved procedure employed to compute the pressures at the GNSS benchmark level. As anticipated, the time series show clear annual and semi-annual signals, with site-dependent amplitude and scatter (Fig. 4, left panels). In addition, many sites also present a strong diurnal signal (e.g. Fig. 4a and c). The autocovariance (ACV) function of the residual time series reveals the magnitude of the temporal correlations present within the data. Clearly, observations with a time difference shorter than 2 weeks could not be assumed as uncorrelated (Fig. 4, right panels). In some cases, besides the inclusion of diurnal parameters in the modelling, these short-term signals are strong enough to produce a recognisable pattern in the ACV function of the corresponding residuals (e.g. Fig. 4a, right panel).

Our IWV estimates were compared with measurements at 13 regional upper-air observation stations. The differences between IWV derived from co-located radiosondes and GNSS show a normal distribution, with mean values between -1 and $+1 \mathrm{~kg} \mathrm{~m}^{-2}$, and a standard deviations below $3 \mathrm{~kg} \mathrm{~m}^{-2}$ (Table 2). Therefore, the accuracy of our IWV estimates is always better than $3 \mathrm{~kg} \mathrm{~m}^{-2}$ and satisfies the requirement for regional climate studies within the Global Climate Observing System (GCOS) specifications (see, for example, EUMETNET, 2010).

The estimates for the mean IWV present a very wide range, from almost zero to $\sim 60 \mathrm{~kg} \mathrm{~m}^{-2}$ (Table 3 and its continuation). Also, the mean IWV values show a clear spatial correlation (Fig. 5a). Both results should be expected, and are mainly related to the climate types at the locations where the
Table 2. Comparison between IWV measured with co-located radiosondes and our GNSS-derived estimates.

\begin{tabular}{lrrr}
\hline Site & $\begin{array}{r}\text { Mean diff. } \\
\mathrm{kg} \mathrm{m}^{-2}\end{array}$ & $\begin{array}{r}\text { SD } \\
\mathrm{kg} \mathrm{m}^{-2}\end{array}$ & $\begin{array}{r}\text { Number of }^{\text {samples }}{ }^{\text {b }} \\
\text { BDOS }\end{array}$ \\
BELE & -0.29 & 2.75 & 1077 \\
BOAV & -0.18 & 1.82 & 1395 \\
BOGT & 0.00 & 1.98 & 1532 \\
CUIB & 0.04 & 1.01 & 1594 \\
IGM1 & -0.43 & 1.55 & 1716 \\
MSCG & 0.04 & 1.55 & 1436 \\
MZAC & 0.68 & 1.28 & 7071 \\
PARC & 0.41 & 1.25 & 1236 \\
PEPE & -0.59 & 1.83 & 1592 \\
POAL & -0.43 & 2.11 & 1325 \\
POLI & -0.50 & 1.51 & 1798 \\
POVE & 0.19 & 2.03 & 1698 \\
\hline
\end{tabular}

${ }^{a}$ Radiosonde minus GNSS. ${ }^{b}$ Daily samples at 12:00 UTC.

GNSS tracking stations are installed. Following the KöppenGeiger climate type classification for the Americas (Fig. 5c), as given by Peel et al. (2007), the analysed sites span from an arid desert in northern Mexico (climate type B) to a polar tundra in southernmost Chile and Argentina (climate type E), with temperate areas and tropical rainforests in between (climate types $\mathrm{C}$ and $\mathrm{A}$, respectively). In addition, some sites show local topographic effects. For example, the relatively low estimate of $\sim 20 \mathrm{~kg} \mathrm{~m}^{-2}$ for the mean IWV above site BOGT, with respect to its neighbour sites, is explained by the high altitude of this station, of about $2500 \mathrm{~m}$ above mean 

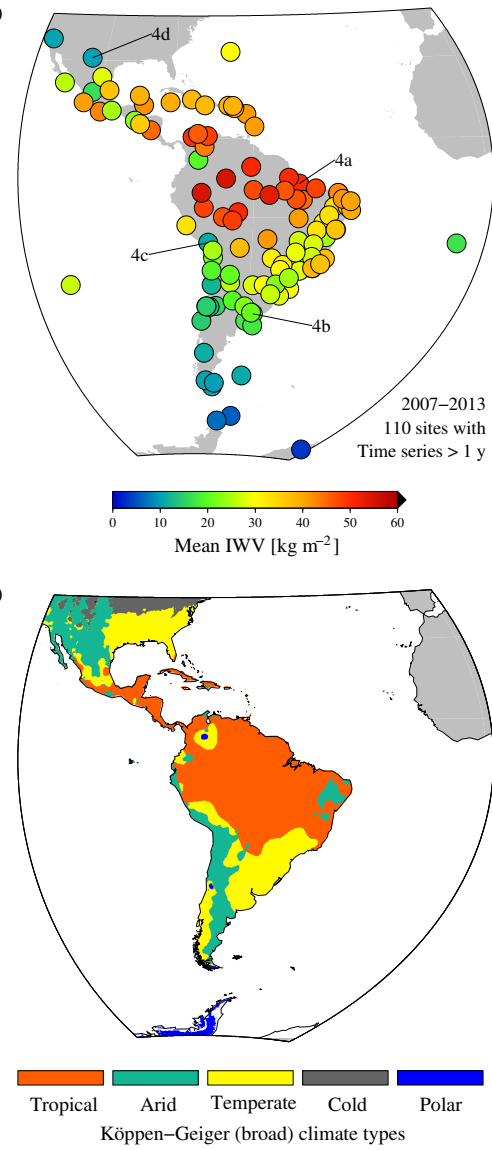

(b)

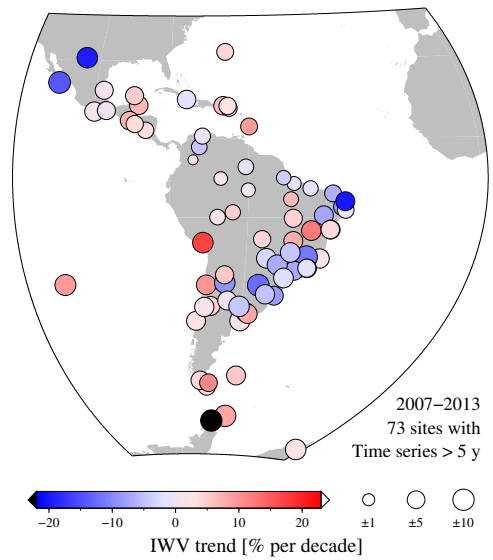

(d)

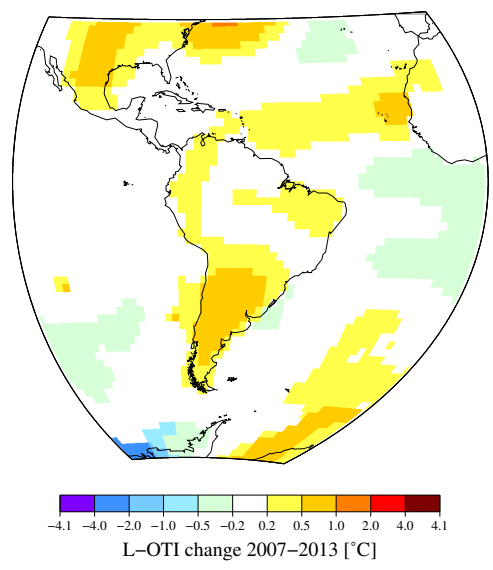

Figure 5. Mean IWV and trends, climate regimes and surface temperature change. (a) Mean IWV estimates. The sites shown in Fig. 4 are also indicated here. (b) Observed local IWV trends. (c) Köppen-Geiger (broad) climate types for the Americas according to Peel et al. (2007). (d) Land-ocean temperature index (L-OTI) change, during 2007-2013, according to GISTEMP Team (2016) (see also Hansen et al., 2010).

(a)

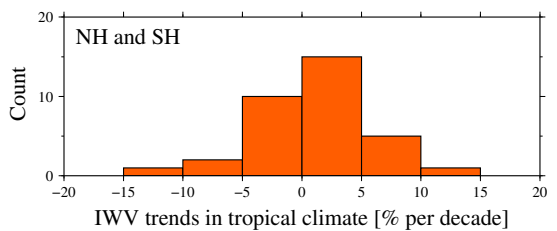

(b)

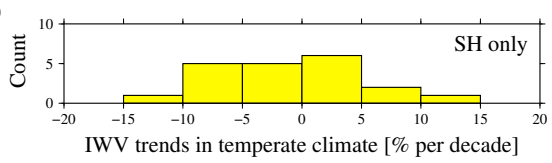

(c)

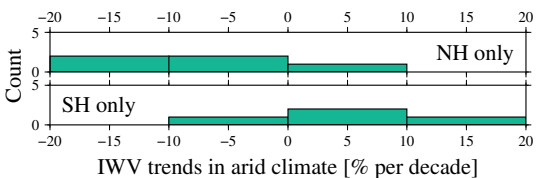

Figure 6. Histograms of the estimated local IWV trends, by climate type. NH and SH mean Northern and Southern Hemisphere, respectively. sea level (Fig. 5a, green circle in northwestern South America).

Clearly, the most interesting results from the IWV analysis are the estimated trends. In this case, the analysis was restricted only to those time series spanning more than 5 years, for a total of 73 sites (Fig. 5b). Although the estimated parameters and their corresponding uncertainties are of the same order of magnitude, some non-null trends result as significant even within their formal errors (Table 3). However, given the limited length of the analysed time series, it could be rather difficult to compute seasonal trends from these data with any reasonable confidence, so no such attempt was made here.

On the other hand, the estimated trends do correlate within regions with similar climate type (Table 4). In particular, temperate regions in South America seem to be drying (Fig. 6b), whereas the tropical areas in Central and South America and the Caribbean, as a whole, seem to be slowly moistening (Fig. 6a). Of course, these inferences could not be conclusive given the inhomogeneous distribution of the GNSS tracking sites within the regions of common climate. Indeed, the dis- 
Table 3. Mean IWV and trends estimated, for the analysed time period, in Central and South America and the Caribbean.

\begin{tabular}{|c|c|c|c|c|c|c|c|c|c|c|}
\hline \multirow[b]{2}{*}{ Site } & \multirow{2}{*}{$\begin{array}{c}\text { Climate } \\
\text { type }^{\mathrm{a}}\end{array}$} & \multirow{2}{*}{$\begin{array}{l}\text { Lat } \\
\text { deg }\end{array}$} & \multirow{2}{*}{$\begin{array}{r}\text { Long } \\
\text { deg }\end{array}$} & \multirow{2}{*}{$\begin{array}{l}\text { Alt. } \\
\text { m }\end{array}$} & \multirow[b]{2}{*}{ start } & \multirow[b]{2}{*}{ end } & \multirow{2}{*}{$\begin{array}{c}\Delta t \\
\mathrm{y}\end{array}$} & \multirow{2}{*}{$\begin{array}{r}\text { Mean IWV } \\
\mathrm{kg} \mathrm{m}^{-2}\end{array}$} & \multicolumn{2}{|c|}{ IWV trend } \\
\hline & & & & & & & & & $\mathrm{kg} \mathrm{m}^{-2}$ decade $^{-1}$ & $\%$ decade $^{-1}$ \\
\hline ACYA & A & 16.837 & -99.902 & 4 & 2007.0 & 2013.4 & 6.4 & $42.8 \pm 0.5$ & $0.5 \pm 2.9$ & $1.1 \pm 6.7$ \\
\hline AREQ & B & -16.465 & -71.492 & 2449 & 2007.0 & 2014.0 & 7.0 & $11.0 \pm 0.2$ & $1.9 \pm 1.0$ & $17.1 \pm 9.0$ \\
\hline AUTF & $\mathrm{E}$ & -54.839 & -68.303 & 58 & 2007.0 & 2014.0 & 7.0 & $10.5 \pm 0.1$ & $0.2 \pm 0.5$ & $1.8 \pm 4.7$ \\
\hline AZUL & $\mathrm{C}$ & -36.767 & -59.881 & 141 & 2007.7 & 2014.0 & 6.3 & $17.6 \pm 0.3$ & $0.3 \pm 1.3$ & $1.7 \pm 7.9$ \\
\hline BDOS & A & 13.087 & -59.609 & 9 & 2007.0 & 2013.9 & 6.9 & $40.8 \pm 0.3$ & $3.7 \pm 1.7$ & $9.2 \pm 4.1$ \\
\hline BELE & A & -1.408 & -48.462 & 34 & 2007.0 & 2014.0 & 7.0 & $50.0 \pm 0.2$ & $-0.8 \pm 1.0$ & $-1.6 \pm 2.0$ \\
\hline BOAV & A & 2.845 & -60.701 & 84 & 2007.7 & 2014.0 & 6.3 & $50.3 \pm 0.3$ & $-0.7 \pm 1.6$ & $-1.3 \pm 3.1$ \\
\hline BOGT & $\mathrm{C}$ & 4.640 & -74.080 & 2553 & 2007.0 & 2014.0 & 7.0 & $19.6 \pm 0.0$ & $0.7 \pm 0.1$ & $3.5 \pm 0.5$ \\
\hline BOMJ & A & -13.255 & -43.421 & 434 & 2007.3 & 2014.0 & 6.7 & $33.0 \pm 0.5$ & $4.0 \pm 2.6$ & $12.1 \pm 7.8$ \\
\hline BRAZ & A & -15.947 & -47.877 & 1118 & 2007.0 & 2014.0 & 7.0 & $27.0 \pm 0.4$ & $2.1 \pm 1.8$ & $7.7 \pm 6.6$ \\
\hline BRFT & A & -3.877 & -38.425 & 30 & 2007.0 & 2014.0 & 7.0 & $42.5 \pm 0.3$ & $-1.6 \pm 1.3$ & $-3.7 \pm 3.2$ \\
\hline BRMU & $\mathrm{C}$ & 32.370 & -64.696 & 20 & 2007.0 & 2014.0 & 7.0 & $29.8 \pm 0.2$ & $1.1 \pm 1.1$ & $4.0 \pm 4.0$ \\
\hline BYSP & A & 18.407 & -66.161 & 93 & 2008.3 & 2014.0 & 5.7 & $38.7 \pm 0.4$ & $2.5 \pm 2.2$ & $6.4 \pm 5.9$ \\
\hline CEEU & A & -3.877 & -38.425 & 30 & 2008.2 & 2014.0 & 5.8 & $43.2 \pm 0.3$ & $-2.7 \pm 1.8$ & $-6.4 \pm 4.1$ \\
\hline CEFE & A & -20.310 & -40.319 & 21 & 2007.6 & 2014.0 & 6.4 & $37.6 \pm 0.5$ & $1.0 \pm 2.6$ & $2.6 \pm 6.9$ \\
\hline CHET & A & 18.495 & -88.299 & 9 & 2007.0 & 2014.0 & 7.0 & $41.8 \pm 0.5$ & $2.9 \pm 2.5$ & $6.9 \pm 5.9$ \\
\hline CHPI & $\mathrm{C}$ & -22.687 & -44.985 & 620 & 2007.5 & 2014.0 & 6.5 & $29.8 \pm 0.3$ & $-2.2 \pm 2.0$ & $-7.3 \pm 6.6$ \\
\hline CONZ & $\mathrm{C}$ & -36.843 & -73.025 & 160 & 2007.0 & 2014.0 & 7.0 & $14.5 \pm 0.2$ & $0.4 \pm 0.9$ & $2.7 \pm 6.2$ \\
\hline $\mathrm{COPO}$ & B & -27.384 & -70.338 & 447 & 2007.0 & 2014.0 & 7.0 & $12.1 \pm 0.2$ & $1.1 \pm 0.9$ & $9.8 \pm 7.3$ \\
\hline CRO1 & A & 17.756 & -64.584 & 11 & 2007.0 & 2014.0 & 7.0 & $38.7 \pm 0.3$ & $1.9 \pm 1.5$ & $4.9 \pm 3.8$ \\
\hline CUCU & A & 7.898 & -72.487 & 310 & 2007.0 & 2014.0 & 7.0 & $43.3 \pm 0.3$ & $-2.0 \pm 1.3$ & $-4.6 \pm 2.9$ \\
\hline CUIB & A & -15.555 & -56.069 & 235 & 2007.0 & 2014.0 & 7.0 & $41.2 \pm 0.4$ & $1.8 \pm 1.8$ & $4.3 \pm 4.3$ \\
\hline EBYP & $\mathrm{C}$ & -27.368 & -55.892 & 128 & 2009.0 & 2014.0 & 5.0 & $29.6 \pm 0.5$ & $-3.7 \pm 3.2$ & $-12.4 \pm 11.1$ \\
\hline FALK & $\mathrm{E}$ & -51.693 & -57.874 & 38 & 2008.6 & 2014.0 & 5.4 & $11.0 \pm 0.1$ & $0.6 \pm 0.7$ & $5.4 \pm 6.3$ \\
\hline GUAT & $\mathrm{C}$ & 14.590 & -90.520 & 1517 & 2007.0 & 2014.0 & 7.0 & $23.1 \pm 0.3$ & $1.7 \pm 1.3$ & $7.3 \pm 6.0$ \\
\hline IGM1 & $\mathrm{C}$ & -34.572 & -58.439 & 34 & 2007.0 & 2014.0 & 7.0 & $20.6 \pm 0.3$ & $0.0 \pm 1.3$ & $0.0 \pm 6.7$ \\
\hline ISPA & A & -27.124 & -109.344 & 116 & 2007.0 & 2014.0 & 7.0 & $26.6 \pm 0.5$ & $2.5 \pm 2.5$ & $9.3 \pm 9.3$ \\
\hline LPAZ & $\mathrm{B}$ & 24.138 & -110.319 & 26 & 2007.0 & 2012.0 & 5.0 & $25.6 \pm 0.4$ & $-3.7 \pm 2.9$ & $-14.3 \pm 11.2$ \\
\hline LPGS & $\mathrm{C}$ & -34.906 & -57.932 & 13 & 2007.0 & 2014.0 & 7.0 & $20.5 \pm 0.3$ & $1.7 \pm 1.3$ & $8.2 \pm 6.8$ \\
\hline MABA & A & -5.362 & -49.122 & 103 & 2007.7 & 2014.0 & 6.3 & $47.1 \pm 0.2$ & $3.2 \pm 1.1$ & $6.7 \pm 2.5$ \\
\hline MANA & A & 12.148 & -86.248 & 66 & 2007.0 & 2014.0 & 7.0 & $45.1 \pm 0.3$ & $1.6 \pm 1.7$ & $3.5 \pm 3.7$ \\
\hline MAPA & A & 0.046 & -51.097 & 19 & 2007.0 & 2014.0 & 7.0 & $50.0 \pm 0.2$ & $-1.9 \pm 1.1$ & $-3.7 \pm 2.2$ \\
\hline MARA & B & 10.673 & -71.624 & 42 & 2007.0 & 2014.0 & 7.0 & $48.2 \pm 0.3$ & $-0.4 \pm 1.6$ & $-0.8 \pm 3.3$ \\
\hline MDO1 & $\mathrm{B}$ & 30.680 & -104.014 & 2026 & 2007.0 & 2013.9 & 6.9 & $10.3 \pm 0.2$ & $-2.0 \pm 0.9$ & $-19.4 \pm 8.7$ \\
\hline MERI & $\mathrm{B}$ & 20.980 & -89.620 & 21 & 2007.0 & 2014.0 & 7.0 & $39.2 \pm 0.4$ & $2.0 \pm 2.2$ & $5.1 \pm 5.6$ \\
\hline MGBH & A & -19.941 & -43.924 & 980 & 2009.0 & 2014.0 & 5.0 & $27.1 \pm 0.5$ & $-3.1 \pm 3.2$ & $-11.3 \pm 11.7$ \\
\hline MSCG & $\mathrm{C}$ & -20.440 & -54.540 & 674 & 2008.0 & 2014.0 & 6.0 & $31.6 \pm 0.5$ & $-1.0 \pm 2.5$ & $-3.1 \pm 7.8$ \\
\hline
\end{tabular}

${ }^{a}$ Köppen-Geiger (broad) climate types, according to Peel et al. (2007); A means tropical, B means arid, C means temperate, and E means polar.

tribution of the sites in South America is clearly biased towards the east. Thus, the negative trend obtained for the temperate areas seems to be determined mainly by a distinctive group of stations in southern Brazil and central-eastern Argentina, all showing a similar diminution in IWV of about $5 \%$ per decade (Fig. 5b). A similar analysis also suggests that the arid areas in the Northern Hemisphere $(\mathrm{NH})$ are drying, while exactly the opposite is occurring in the arid areas of the Southern Hemisphere (SH, Fig. 6c), but in this case the number of sites averaged is quite small, resulting in far less significant trends (Table 4). In any case, the prolonged drought experienced by Brazil, mainly in the northeast but also in the south (Gutiérrez et al., 2014), is quite evident in our results (Fig. 5b). In this case the negative IWV trends we obtained are mainly driven by the recent dry years ex- perienced in these temperate and tropical areas (years 2010, 2012, 2013, and 2014; Marengo and Bernasconi, 2014).

The relation between the estimated local IWV trends and the observed temperature changes, within the analysed time period, seems to also depend on the climate regime. The observed moistening of the troposphere, in Patagonia and most arid regions in South America, coincides with a moderate increase in surface temperatures (Fig. 5d). Similarly, a slight temperature increase also coincides with the observed slow average moistening of the atmosphere over the tropical regions. In contrast, the moderate increase in surface temperatures observed over temperate regions in South America coincides with the drying of the troposphere.

It is worth noting that the estimated IWV trends are only valid for the given time span and should not be regarded as long-term signals without further considerations. For ex- 
Table 3. Continued.

\begin{tabular}{|c|c|c|c|c|c|c|c|c|c|c|}
\hline \multirow[b]{2}{*}{ Site } & \multirow{2}{*}{$\begin{array}{c}\text { Climate } \\
\text { type }^{\mathrm{a}}\end{array}$} & \multirow{2}{*}{$\begin{array}{l}\text { Lat } \\
\text { deg }\end{array}$} & \multirow{2}{*}{$\begin{array}{r}\text { Long } \\
\text { deg }\end{array}$} & \multirow{2}{*}{$\begin{array}{l}\text { Alt. } \\
\text { m }\end{array}$} & \multirow[b]{2}{*}{ Start } & \multirow[b]{2}{*}{ End } & \multirow{2}{*}{$\begin{array}{c}\Delta t \\
\mathrm{y}\end{array}$} & \multirow{2}{*}{$\begin{array}{r}\text { Mean IWV } \\
\mathrm{kg} \mathrm{m}^{-2}\end{array}$} & \multicolumn{2}{|c|}{ IWV trend } \\
\hline & & & & & & & & & $\mathrm{kg} \mathrm{m}^{-2}$ decade $^{-1}$ & $\%$ decade $^{-1}$ \\
\hline MZAC & B & -32.895 & -68.875 & 837 & 2007.0 & 2014.0 & 7.0 & $15.5 \pm 0.2$ & $0.7 \pm 1.0$ & $4.4 \pm 6.4$ \\
\hline NAUS & A & -3.022 & -60.055 & 105 & 2007.0 & 2014.0 & 7.0 & $47.6 \pm 0.2$ & $0.4 \pm 0.9$ & $0.8 \pm 1.8$ \\
\hline OAX2 & $\mathrm{B}$ & 17.078 & -96.716 & 1608 & 2007.0 & 2013.7 & 6.7 & $24.3 \pm 0.3$ & $-0.1 \pm 1.3$ & $-0.4 \pm 5.3$ \\
\hline $\mathrm{OHI} 2^{\mathrm{b}}$ & $\mathrm{E}$ & -63.321 & -57.901 & 9 & 2007.0 & 2014.0 & 7.0 & $5.9 \pm 0.1$ & $0.5 \pm 0.6$ & $8.4 \pm 10.1$ \\
\hline ONRJ & A & -22.895 & -43.224 & 41 & 2007.2 & 2013.9 & 6.6 & $37.0 \pm 0.4$ & $-1.1 \pm 2.2$ & $-2.9 \pm 5.9$ \\
\hline PALM $^{b}$ & $\mathrm{E}$ & -64.775 & -64.051 & 14 & 2007.0 & 2014.0 & 7.0 & $6.9 \pm 0.1$ & $-3.2 \pm 0.7$ & $-47.8 \pm 10.1$ \\
\hline PARC & $\mathrm{C}$ & -53.136 & -70.879 & 12 & 2007.0 & 2014.0 & 7.0 & $10.5 \pm 0.1$ & $0.4 \pm 0.6$ & $3.7 \pm 5.6$ \\
\hline PBCG & A & -7.213 & -35.907 & 538 & 2008.3 & 2014.0 & 5.7 & $33.8 \pm 0.3$ & $-3.2 \pm 1.7$ & $-9.4 \pm 5.0$ \\
\hline PEPE & $\mathrm{B}$ & -9.384 & -40.506 & 382 & 2008.0 & 2014.0 & 6.0 & $33.6 \pm 0.4$ & $-2.5 \pm 2.1$ & $-7.4 \pm 6.2$ \\
\hline POAL & $\mathrm{C}$ & -30.074 & -51.119 & 71 & 2007.1 & 2014.0 & 6.9 & $27.8 \pm 0.3$ & $-2.2 \pm 1.8$ & $-8.2 \pm 6.4$ \\
\hline POLI & $\mathrm{C}$ & -23.555 & -46.730 & 733 & 2007.0 & 2014.0 & 7.0 & $28.1 \pm 0.3$ & $-2.0 \pm 1.8$ & $-7.0 \pm 6.3$ \\
\hline POVE & A & -8.709 & -63.896 & 107 & 2007.0 & 2014.0 & 7.0 & $50.6 \pm 0.3$ & $2.3 \pm 1.3$ & $4.7 \pm 2.7$ \\
\hline PPTE & $\mathrm{C}$ & -22.119 & -51.408 & 436 & 2007.5 & 2014.0 & 6.5 & $31.6 \pm 0.5$ & $-2.2 \pm 2.6$ & $-6.9 \pm 8.2$ \\
\hline RECF & A & -8.050 & -34.951 & 25 & 2007.0 & 2014.0 & 7.0 & $39.6 \pm 0.3$ & $-0.1 \pm 1.5$ & $-0.2 \pm 3.7$ \\
\hline RIO2 & $\mathrm{C}$ & -53.785 & -67.751 & 19 & 2007.3 & 2014.0 & 6.7 & $10.0 \pm 0.1$ & $1.1 \pm 0.5$ & $11.0 \pm 5.0$ \\
\hline RIOB & A & -9.965 & -67.802 & 147 & 2007.3 & 2014.0 & 6.7 & $47.0 \pm 0.3$ & $1.0 \pm 1.5$ & $2.1 \pm 3.1$ \\
\hline RIOD & A & -22.817 & -43.306 & 14 & 2007.0 & 2014.0 & 7.0 & $38.2 \pm 0.4$ & $-0.8 \pm 2.0$ & $-2.0 \pm 5.2$ \\
\hline RNNA & A & -5.836 & -35.207 & 50 & 2009.0 & 2014.0 & 5.0 & $40.3 \pm 0.4$ & $-8.0 \pm 2.6$ & $-20.0 \pm 6.4$ \\
\hline SAGA & A & -0.143 & -67.057 & 90 & 2007.7 & 2014.0 & 6.3 & $54.8 \pm 0.2$ & $1.3 \pm 1.0$ & $2.5 \pm 1.8$ \\
\hline SALU & A & -2.593 & -44.212 & 44 & 2007.7 & 2014.0 & 6.3 & $48.2 \pm 0.2$ & $-0.8 \pm 1.3$ & $-1.6 \pm 2.6$ \\
\hline SANT & $\mathrm{C}$ & -33.150 & -70.668 & 695 & 2007.0 & 2013.3 & 6.3 & $12.4 \pm 0.2$ & $0.2 \pm 0.9$ & $1.6 \pm 7.2$ \\
\hline SAVO & A & -12.939 & -38.432 & 87 & 2007.7 & 2014.0 & 6.3 & $35.7 \pm 0.4$ & $1.3 \pm 2.2$ & $3.9 \pm 6.1$ \\
\hline SCUB & A & 20.012 & -75.762 & 44 & 2007.0 & 2013.5 & 6.5 & $38.2 \pm 0.4$ & $-0.8 \pm 2.2$ & $-2.0 \pm 6.0$ \\
\hline SMAR & $\mathrm{C}$ & -29.718 & -53.716 & 103 & 2007.0 & 2014.0 & 7.0 & $26.6 \pm 0.4$ & $-1.3 \pm 1.8$ & $-4.8 \pm 6.7$ \\
\hline SSA1 & A & -12.975 & -38.516 & 8 & 2007.7 & 2014.0 & 6.3 & $36.7 \pm 0.4$ & $1.3 \pm 2.1$ & $3.8 \pm 5.7$ \\
\hline SSIA & A & 13.697 & -89.116 & 625 & 2007.3 & 2014.0 & 6.7 & $35.7 \pm 0.4$ & $1.3 \pm 1.6$ & $3.6 \pm 4.4$ \\
\hline TAMP & A & 22.278 & -97.864 & 37 & 2007.0 & 2014.0 & 7.0 & $37.1 \pm 0.4$ & $0.4 \pm 2.0$ & $1.0 \pm 5.3$ \\
\hline TOPL & A & -10.171 & -48.330 & 274 & 2008.0 & 2014.0 & 6.0 & $41.0 \pm 0.4$ & $1.8 \pm 2.2$ & $4.3 \pm 5.3$ \\
\hline TUCU & $\mathrm{C}$ & -26.843 & -65.230 & 456 & 2007.0 & 2013.9 & 6.9 & $26.1 \pm 0.4$ & $-2.3 \pm 2.3$ & $-9.1 \pm 9.1$ \\
\hline UBER & $\mathrm{C}$ & -18.889 & -48.316 & 802 & 2007.5 & 2014.0 & 6.5 & $28.8 \pm 0.4$ & $-1.3 \pm 2.2$ & $-4.5 \pm 7.6$ \\
\hline UCOR & $\mathrm{C}$ & -31.434 & -64.193 & 437 & 2007.0 & 2014.0 & 7.0 & $19.6 \pm 0.3$ & $0.0 \pm 1.3$ & $0.0 \pm 6.6$ \\
\hline UFPR & $\mathrm{C}$ & -25.448 & -49.230 & 921 & 2007.7 & 2014.0 & 6.3 & $24.3 \pm 0.3$ & $-0.6 \pm 1.9$ & $-2.4 \pm 7.8$ \\
\hline UNRO & $\mathrm{C}$ & -32.959 & -60.628 & 49 & 2007.0 & 2014.0 & 7.0 & $22.5 \pm 0.4$ & $-1.0 \pm 2.0$ & $-4.4 \pm 8.8$ \\
\hline UNSA & $\mathrm{C}$ & -24.727 & -65.407 & 1224 & 2007.0 & 2014.0 & 7.0 & $20.6 \pm 0.2$ & $1.1 \pm 1.1$ & $5.3 \pm 5.3$ \\
\hline VESL $^{b}$ & $\mathrm{E}$ & -71.673 & -2.841 & 852 & 2007.2 & 2013.0 & 5.8 & $3.2 \pm 0.1$ & $0.1 \pm 0.3$ & $3.0 \pm 9.0$ \\
\hline VITH & A & 18.343 & -64.969 & 48 & 2007.0 & 2014.0 & 7.0 & $39.0 \pm 0.3$ & $1.1 \pm 1.7$ & $2.8 \pm 4.3$ \\
\hline
\end{tabular}

a Köppen-Geiger (broad) climate types, according to Peel et al. (2007); A means tropical, B means arid, C means temperate, and E means polar. ${ }^{\mathrm{b}}$ Antarctica.

Table 4. Mean IWV trends computed within regions of similar climate types, in Central and South America and the Caribbean, between January 2007 and December 2013. NH and SH mean Northern and Southern Hemisphere, respectively.

\begin{tabular}{lcc}
\hline $\begin{array}{l}\text { Climate } \\
\text { type }\end{array}$ & $\begin{array}{c}\text { Mean IWV trend } \\
\text { in \% per decade }\end{array}$ & $\begin{array}{c}\text { Number } \\
\text { of sites }\end{array}$ \\
\hline Tropical (NH and SH) & $+0.7 \pm 1.1$ & $35^{\mathrm{a}}$ \\
Temperate (SH) & $-1.8 \pm 1.4$ & 20 \\
Arid (NH) & $-6.0 \pm 4.6$ & 5 \\
Arid (SH) & $+6.0 \pm 5.2$ & 4 \\
\hline
\end{tabular}

a The site ISPA was not included (Easter Island).

ample, in our crude analysis no attempt was made to isolate the possible effects of the moderate El Niño SouthernOscillation (ENSO) events occurring within the observed time period (La Niña in 2007-2008 and 2010-2011; Huang et al., 2015), although the associated IWV variability could be significant (Trenberth et al., 2005). Also, note that none of the analysed time series span more than 7 years. Optimally, given the sensitivity of the trends to the specific time period analysed (Steigenberger et al., 2007), at least a decade of data should be required in order to infer significant longterm variability for these atmospheric parameters. In essence, to obtain more stable trends, longer time series are required. Nonetheless, despite these shortcomings, the spatial correlation shown by the parameters estimated within particular regions, with similar climate regimes, suggests that some trends are significant and evince real changes in the amount or distribution of the atmospheric water vapour over the region under study. 


\section{Conclusions}

Evidence of drying of the troposphere over temperate regions in South America has been found, at a mean IWV rate of approximately $2 \%$ per decade, particularly in southern Brazil and central-eastern Argentina. Although the GNSS analysis only spanned 7 years, the introduction of significant temporal correlation produced reliable trends, with realistic uncertainties. The results also suggest a slow troposphere moistening at the tropics, but this inference is less conclusive. Nevertheless, the trends estimated are only valid for the given time span and could not be regarded as long-term signals.

The regional, multi-year analysis has also made possible a robust performance assessment of the GPT2w blind model and, indirectly, its underlying NWM (i.e. ERA-Interim). The analysis showed the good general agreement between observed and modelled mean delays, but it also revealed some limitations (up to $20 \mathrm{~mm}$ in ZTD). These biases are probably related to the less-than-optimal availability of regional water vapour measurements (radiosondes) for the assimilation process. For practical applications, requiring near-the-horizon and highly precise troposphere slant delays, local mean corrections could be useful.
Furthermore, the complete data set has been made openly available as supplementary material (Bianchi et al., 2016). This multi-year, high-rate and homogeneous analysis, comprising more than a hundred GNSS tracking sites, and specifically aimed for atmosphere IWV retrieval, has no precedent in the region under study, particularly in South America. In the future, the computation of longer time series, together with the inclusion of additional and better distributed GNSS sites, will surely help to increase the potential uses of the data collection for climate studies.

\section{Data availability}

All underlying data for this research, including GNSS observations and meteorological measurements, can be openly accessed from the respective data repositories of the organisations and agencies mentioned below (see Acknowledgements). This ensures the entire reproducibility of the present work. 


\section{Appendix A: Atmospheric pressure at the GNSS sites}

In this work, atmospheric pressure time series from several sources were combined in order to retrieve IWV estimates from observed ZTDs. In the following sections we give a precise description of the procedures applied to the original records of each data set in order to obtain consistent pressures at the GNSS sites.

\section{A1 Outlier detection in pressure time series}

Before any computation, the pressure time series from each synoptic station were screened for unrealistic values. In general, this issue involves simultaneously several fields, including pressure and air temperature records. As noted by Wang et al. (2007), the data set provided by the IGS (i.e. RINEX m-files) resulted as particularly noisy and should not be employed without rigorous cleaning.

The procedure was performed on a station-per-station basis and comprises two steps. Firstly, successive records were screened for pressure rates exceeding $\pm 6 \mathrm{hPa}$ per hour, which are probably only possible in extremely severe weather conditions (Nott, 2006). Secondly, the standard deviations, $\sigma$, of the remaining records were computed. Those records departing more than $4 \sigma$ from the mean were also discarded. In total, $0.07,0.17$, and $12.5 \%$ of the available records were regarded as outliers, from UW, NOAA, and IGS data sets, respectively, and therefore were not employed.

\section{A2 Pressures from IGS data set}

In situ synoptic atmospheric observations at some GNSS tracking sites are provided by the IGS by means of RINEX $\mathrm{m}$-files. The geodetic height differences $(\Delta h)$ from barometers to GNSS benchmarks are available in the log files of each site or directly in the RINEX headers. In the present study $\Delta h$ ranged from -4.2 to $15 \mathrm{~m}$. For this reason $\Delta h$ was simply assimilated to a geopotential height difference $(\Delta z)$.

Then, assuming a standard atmosphere, the pressure $P$ at the GNSS benchmark can be approximated by means of the barometric height formula (Zdunkowski and Bott, 2004)

$P=P_{0}\left(\frac{T_{0}-L \Delta z}{T_{0}}\right)^{\frac{g_{45}}{R L}}$

where $P_{0}$ and $T_{0}$ are the observed atmospheric pressure and air temperature, respectively, $L$ is the assumed lapse rate of the temperature $\left(0.006499 \mathrm{~K} \mathrm{~m}^{-1}\right), g_{45}$ is the normal gravity at $45^{\circ}$ latitude $\left(9.80665 \mathrm{~m} \mathrm{~s}^{-2}\right)$, and $R$ is the gas constant of dry air $\left(287.05 \mathrm{~J} \mathrm{~kg}^{-1} \mathrm{~K}^{-1}\right)$.

\section{A3 Pressures from NOAA data set}

The ISD-lite product from NOAA provides several fields, including atmospheric pressure records reduced to mean sea level (ftp://ftp.ncdc.noaa.gov/pub/data/noaa/isd-lite/).
Thereafter, this level of reference is approximated here to a constant orthometric height $H_{0}=0 \mathrm{~m}$ for all synoptic stations. By means of the geoid undulation $N$ at the location of the GNSS station, computed in this case with help of the geopotential model EGM2008 (Pavlis et al., 2012), the orthometric height $H$ at the GNSS benchmark can be approximated as $H=h-N$, where the corresponding geodetic height $h$ is known. In this work $N$ ranged from -48 to $40 \mathrm{~m}$.

The relation between orthometric (i.e. geometric) heights $H$ and geopotential heights $z$ is given by (see, for example, van Dam et al., 2010)

$z(H, \varphi)=\frac{g(\varphi)}{g_{45}} \frac{r(\varphi) H}{r(\varphi)+H}$,

where $r(\varphi)$ represents the radius at latitude $\varphi$ over the chosen reference ellipsoid, in this case WGS84 (NIMA, 2000), whereas $g(\varphi)$ is the normal gravity at the same latitude.

The radius $r(\varphi)$ can be computed as

$r(\varphi)=\left(\frac{\cos ^{2} \varphi}{a^{2}}+\frac{\sin ^{2} \varphi}{b^{2}}\right)^{-\frac{1}{2}}$,

where $a$ and $b$ are the semi-major and semi-minor axes of the reference ellipsoid. In this case, $a=6378137.0 \mathrm{~m}$ and $b=6356752.3 \mathrm{~m}$.

The normal gravity $g(\varphi)$ can be computed as

$g(\varphi)=g_{\mathrm{e}} \frac{1+k_{\mathrm{s}} \sin ^{2} \varphi}{\sqrt{1-e^{2} \sin ^{2} \varphi}}$,

where $e$ represents the eccentricity of the reference ellipsoid (0.0066943800229), whereas $g_{\mathrm{e}}$ corresponds to the normal gravity at the Equator $\left(9.7803267714 \mathrm{~ms}^{-2}\right)$ and $k_{\mathrm{s}}$ is Somigliana's constant $\left(1.931853 \times 10^{-3}\right)$.

By means of Eq. (A2) the geopotential heights $z_{0}$ and $z$, at the pressure reference level and the GNSS benchmark, respectively, can be computed. Then, the pressure $P$ at the GNSS benchmark can be obtained from Eq. (A1), where $\Delta z=z-z_{0}$ and $P_{0}$ and $T_{0}$ are known. It is worth noting that no actual information about the altitude of the synoptic station is required.

\section{A4 Pressures from UW data set}

The UW data set includes, among many other fields, global observations of surface atmospheric pressure and temperature (http://weather.uwyo.edu/). In this case the pressures are expressed as altimeter settings (http://www.srh.noaa.gov/ images/epz/wxcalc/altimeterSetting.pdf) from which raw pressures, as measured by the stations, could be retrieved.

In practice, the following expression was iteratively solved for $P_{0}$

$P_{0}=A_{0}\left(\frac{L H_{0}}{T_{\text {std }}}\left(\frac{P_{\text {std }}}{P_{0}-C}\right)^{\frac{g_{45}}{R L}}+1\right)^{-\frac{R L}{g_{45}}}+C$ 
where $A_{0}$ is the corresponding altimeter setting, $H_{0}$ is the altitude of the station above mean sea level, $C$ is a conventional offset $(0.3 \mathrm{~h} \mathrm{~Pa})$, and $P_{\text {std }}$ and $T_{\text {std }}$ are standard pressure and temperature at mean sea level $(1013.25 \mathrm{hPa}$ and $288.15 \mathrm{~K}$, respectively).

The orthometric height of the station was approximated by the altitude $H_{0}$, while the orthometric height of the GNSS benchmark results in $H=h-N$, where the geoid undulation $N$ at the GNSS station location was computed with help of a geopotential model (EGM2008; Pavlis et al., 2012). By means of Eq. (A2) the geopotential heights $z_{0}$ and $z$, at the barometer level and the GNSS benchmark, respectively, can be computed. Then, the pressure $P$ at the GNSS benchmark can be obtained from Eq. (A1), where $\Delta z=z-z_{0}$ and $P_{0}$ and $T_{0}$ are known.
It is worth noting that, for a few synoptic stations, the altitudes reported by UW and NOAA are not coincident, with differences reaching hundreds of metres in same cases. For this reason a direct comparison was performed, between raw pressure measurements obtained from an alternative source (Servicio Meteorológico Nacional from Argentina, http://www.smn.gov.ar) and pressures computed with Eq. (A5). This analysis revealed that the altimeter settings from UW data set are consistent with the altitudes provided by NOAA (http://www.nws.noaa.gov/tg/siteloc.php). Therefore, altitudes $H_{0}$ as reported by NOAA were employed for all computations. 
Acknowledgements. We would like to thank the people, organisations, and agencies responsible for collecting, computing, maintaining, and openly providing the observations and products employed in this work: the International GNSS Service (IGS, http://www.igs.org) and its associated analysis centres, Systéme d'Observation du Niveau des Eaux Littorales (SONEL, http://www.sonel.org) and its many contributing organisations, Instituto Brasileiro de Geografia e Estatística (IBGE, Brasil, http://www.ibge.gov.br), Instituto Geográfico Nacional (IGN, Argentina, http://www.ign.gob.ar), the University of Wyoming (UW, USA, http://weather.uwyo.edu), the National Oceanic and Atmospheric Administration (NOAA, USA, http://www.noaa.gov), and Servicio Meteorológico Nacional (SMN, Argentina, http://www.smn.gov.ar). Also, we thank the people at PANGAEA (http://www.pangaea.de), and particularly Stefanie Schumacher, for the significant assistance in publishing the results of this work as an open-access, supplementary data collection. Finally, we thank the two anonymous reviewers for their insightful comments on the original manuscript.

Edited by: M. Salzmann

Reviewed by: two anonymous referees

\section{References}

Adams, D. K., Fernandes, R. M. S., Holub, K. L., Gutman, S. I., Barbosa, H. M. J., Machado, L. A. T., Calheiros, A. J. P., Bennett, R. A., Kursinski, E. R., Sapucci, L. F., DeMets, C., Chagas, G. F. B., Arellano, A., Filizola, N., Amorim Rocha, A. A., Silva, R. A., Assunção, L. M. F., Cirino, G. G., Pauliquevis, T., Portela, B. T. T., Sá, A., de Sousa, J. M., and Tanaka, L. M. S.: The Amazon Dense GNSS Meteorological Network: A New Approach for Examining Water Vapor and Deep Convection Interactions in the Tropics, B. Am. Meteorol. Soc., 96, 2151-2165, doi:10.1175/BAMS-D-13-00171.1, 2015.

Askne, J. and Nordius, H.: Estimation of tropospheric delay for microwaves from surface weather data, Radio Sci., 22, 379-386, doi:10.1029/RS022i003p00379, 1987.

Bevis, M., Businger, S., Herring, T. A., Rocken, C., Anthes, R. A., and Ware, R. H.: GPS meteorology: Remote sensing of atmospheric water vapor using the global positioning system, J. Geophys. Res.-Atmos., 97, 15787-15801, doi:10.1029/92JD01517, 1992.

Bevis, M., Businger, S., Chiswell, S., Herring, T. A., Anthes, R. A., Rocken, C., and Warre, R. H.: GPS Meteorology: Mapping Zenith Wet Delays onto Precipitable Water, J. Appl. Meteorol., 33, 379-386, doi:10.1175/15200450(1994)033<0379:GMMZWD>2.0.CO;2, 1994.

Bianchi, C., Mendoza, L. P. O., Fernández, L., Natali, M. P., Meza, A., and Moirano, J.: Time series of atmospheric water vapour and troposphere zenith total delay, over Central and South America, from a homogeneous GNSS reprocessing (MAGGIA ZTD \& IWV Solution 1), PANGAEA Data Publisher for Earth \& Environmental Science, doi:10.1594/PANGAEA.858234, 2016.

Böhm, J., Niell, A., Tregoning, P., and Schuh, H.: Global Mapping Function (GMF): A new empirical mapping function based on numerical weather model data, Geophy. Res. Lett., 33, L07304, doi:10.1029/2005GL025546, 2006a.
Böhm, J., Werl, B., and Schuh, H.: Troposphere mapping functions for GPS and very long baseline interferometry from European Centre for Medium-Range Weather Forecasts operational analysis data, J. Geophys. Res.-Sol. Ea., 111, B02406, doi:10.1029/2005JB003629, available at: http:// ggosatm.hg.tuwien.ac.at/DELAY/GRID/VMFG/ (last access: 29 August 2015), 2006b.

Böhm, J., Möller, G., Schindelegger, M., Pain, G., and Weber, R.: Development of an improved empirical model for slant delays in the troposphere (GPT2w), GPS Solut., 19, 433-441, doi:10.1007/s10291-014-0403-7, available at: http://ggosatm.hg tuwien.ac.at/DELAY/SOURCE/GPT2w/, last access: 8 September 2015 .

Byun, S. H. and Bar-Sever, Y. E.: A new type of troposphere zenith path delay product of the international GNSS service, J. Geodyn., 83, 1-7, doi:10.1007/s00190-008-0288-8, 2009.

Calori, A., Colosimo, G., Crespi, M., and Mackern, M. V.: International Association of Geodesy Symposia, chap. Comparison of Different Techniques for Tropospheric Wet Delay Retrieval Over South America and Surrounding Oceans, Springer Berlin Heidelberg, Berlin, Heidelberg, Germany, 1-7, doi:10.1007/1345_2015_6, 2015.

Chen, G. and Herring, T. A.: Effects of atmospheric azimuthal asymmetry on the analysis of space geodetic data, J. Geophys. Res.-Sol. Ea., 102, 20489-20502, doi:10.1029/97JB01739, 1997.

Dach, R., Schaer, S., Arnold, D., Orliac, E., Prange, L., Susnik, A., Villiger, A., and Jaeggi, A.: CODE final product series for the IGS, Pulished by Astronomical Institute, University of Bern, Bern, Switzerland, doi:10.7892/boris.75876, available at: http://www.aiub.unibe.ch/download/CODE (last access: 14 April 2015), 2016.

Dach, R., Andritsch, F., Arnold, D., Bertone, S., Fridez, P., Jäggi, A., Jean, Y., Maier, A., Mervart, L., Meyer, U., Orliac, E., Ortiz-Geist, E., Prange, L., Scaramuzza, S., Schaer, S., Sidorov, D., Sušnik, A., Villiger, A., Walser, P., Baumann, C., Beutler, G., Bock, H., Gäde, A., Lutz, S., Meindl, M., Ostini, L., Sośnica, K., Steinbach, A., and Thaller, D.: Bernese GNSS Software Version 5.2, University of Bern, doi:10.7892/boris.72297, http://www.bernese.unibe.ch, 2015.

Davis, J. L., Herring, T. A., Shapiro, I. I., Rogers, A. E. E., and Elgered, G.: Geodesy by radio interferometry: Effects of atmospheric modeling errors on estimates of baseline length, Radio Sci., 20, 1593-1607, doi:10.1029/RS020i006p01593, 1985.

de Haan, S., Barlag, S., Baltink, H. K., Debie, F., and van der Marel, H.: Synergetic Use of GPS Water Vapor and Meteosat Images for Synoptic Weather Forecasting, J. Appl. Meteorol., 43, 514-518, doi:10.1175/15200450(2004)043<0514:SUOGWV>2.0.CO;2, 2004.

de Haan, S., Holleman, I., and Holtslag, A. A. M.: Real-Time Water Vapor Maps from a GPS Surface Network: Construction, Validation, and Applications, J. Appl. Meteorol. Clim., 48, 1302-1316, doi:10.1175/2008JAMC2024.1, 2009.

Dee, D. P., Uppala, S. M., Simmons, A. J., Berrisford, P., Poli, P., Kobayashi, S., Andrae, U., Balmaseda, M. A., Balsamo, G., Bauer, P., Bechtold, P., Beljaars, A. C. M., van de Berg, L., Bidlot, J., Bormann, N., Delsol, C., Dragani, R., Fuentes, M., Geer, A. J., Haimberger, L., Healy, S. B., Hersbach, H., Hólm, E. V., Isaksen, L., Kållberg, P., Köhler, M., Matricardi, M., McNally, 
A. P., Monge-Sanz, B. M., Morcrette, J.-J., Park, B.-K., Peubey, C., de Rosnay, P., Tavolato, C., Thépaut, J.-N., and Vitart, F.: The ERA-Interim reanalysis: configuration and performance of the data assimilation system, Q. J. Roy. Meteor. Soc., 137, 553-597, doi:10.1002/qj.828, available at: http://apps.ecmwf.int/datasets/ data/interim-full-daily/levtype=pl/ (last access: 26 May 2016), 2011.

Dow, J. M., Neilan, R. E., and Rizos, C.: The International GNSS Service in a changing landscape of Global Navigation Satellite Systems, J. Geodyn., 83, 191-198, doi:10.1007/s00190-0080300-3, available at: ftp://cddis.gsfc.nasa.gov/gps/data/ (last access 28 March 2016), 2009.

Duan, J., Bevis, M., Fang, P., Bock, Y., Chiswell, S., Businger, S., Rocken, C., Solheim, F., van Hove, T., Ware, R., McClusky, S., Herring, T. A., and King, R. W.: GPS Meteorology: Direct Estimation of the Absolute Value of Precipitable Water, J. Appl. Meteorol., 35, 830-838, doi:10.1175/15200450(1996)035<0830:GMDEOT>2.0.CO;2, 1996.

EUMETNET: EIG EUMETNET GNSS Water Vapour Programme (E-GVAP-II), Product Requirements Document Version 1.0, European Meteorological Services Network, Avenue Circulaire 3, 1180 Bruxelles, Belgique, available at: http://egvap.dmi.dk/ support/formats/egvap_prd_v10.pdf (last access: 19 May 2016), 2010.

Feaux, K., Braun, J. J., Calais, E., Dausz, K., Friesen, B. T., Mattioli, G. S., Miller, M. M., Normandeau, J., Seider, E., and Wang, G.: COCONet (Continuously Operating Caribbean GPS Observational Network): Network Status and Project Highlights, in: AGU Fall Meeting 2012, American Geophysical Union, San Francisco, CA, USA, available at: http://abstractsearch.agu. org/meetings/2012/FM/T41A-2556.html, abstract T41A-2556, 2012.

Fernández, L., Salio, P., Natali, M. P., and Meza, A.: Estimation of the precipitable water vapor from GPS measurements in Argentina: validation and qualitative analysis of the results, Adv. Space Res., 46, 879-894, doi:10.1016/j.asr.2010.05.012, 2010.

Fritsche, M., Dietrich, R., Knöfel, C., Rülke, A., Vey, S., Rothacher, M., and Steigenberger, P.: Impact of higher-order ionospheric terms on GPS estimates, Geophy. Res. Lett., 32, L23311, doi:10.1029/2005GL024342, 2005.

GISTEMP Team: GISS Surface Temperature Analysis (GISTEMP), NASA Goddard Institute for Space Studies, available at: http: //data.giss.nasa.gov/gistemp/, last access: 30 May 2016.

Gutiérrez, A. P. A., Engle, N. L., De Nys, E., Molejón, C., and Martins, E. S.: Drought preparedness in Brazil, Weather and Climate Extremes, High Level Meeting on National Drought Policy, 3, 95-106, doi:10.1016/j.wace.2013.12.001, 2014.

Hansen, J., Ruedy, R., Sato, M., and Lo, K.: Global Surface Temperature Change, Rev. Geophys., 48, RG4004, doi:10.1029/2010RG000345, 2010.

Hartmann, D. L., Klein Tank, A., Rusticucci, M., Alexander, L. V., Brönnimann, S., Charabi, Y., Dentener, F. J., Dlugokencky, E. J., Easterling, D. R., Kaplan, A., Soden, B. J., Thorne, P. W., Wildm, M., and Zhai, P.: Climate Change 2013: The Physical Science Basis. Contribution of Working Group I to the Fifth Assessment Report of the Intergovernmental Panel on Climate Change, chap. Observations: Atmosphere and Surface, Cambridge University Press, Cambridge, UK and New York, NY, USA, available at: http://www.ipcc.ch/pdf/assessment-report/
ar5/wg1/WG1AR5_Chapter02_FINAL.pdf (last access: 4 February 2016), 2013.

Heise, S., Dick, G., Gendt, G., Schmidt, T., and Wickert, J.: Integrated water vapor from IGS ground-based GPS observations: initial results from a global 5-min data set, Ann. Geophys., 27, 2851-2859, doi:10.5194/angeo-27-2851-2009, 2009.

Huang, B., Banzon, V. F., Freeman, E., Lawrimore, J., Liu, W., Peterson, T. C., Smith, T. M., Thorne, P. W., Woodruff, S. D., and Zhang, H.-M.: Extended Reconstructed Sea Surface Temperature Version 4 (ERSST.v4). Part I: Upgrades and Intercomparisons, J. Climate, 28, 911-930, doi:10.1175/JCLI-D-14-00006.1, 2015.

Instituto Brasileiro de Geografia e Estatística: RBMC GNSS data set, available at: ftp://geoftp.ibge.gov.br/informacoes_sobre_ posicionamento_geodesico/rbmc/dados/, last access: 28 March 2016.

Instituto Geográfico Nacional: RAMSAC GNSS data set, available at: http://www.ign.gob.ar/NuestrasActividades/Geodesia/ Ramsac/DescargaRinex, last access: 15 March 2016.

Jin, S., Park, J.-U., Cho, J.-H., and Park, P.-H.: Seasonal variability of GPS-derived zenith tropospheric delay (1994-2006) and climate implications, J. Geophys. Res.-Atmos., 112, D09110, doi:10.1029/2006JD007772, 2007.

Karabatić, A., Weber, R., and Haiden, T.: Near real-time estimation of tropospheric water vapour content from ground based GNSS data and its potential contribution to weather now-casting in Austria, Adv. Space Res., 47, 1691-1703, doi:10.1016/j.asr.2010.10.028, 2011.

Lagler, K., Schindelegger, M., Böhm, J., Krásná, H., and Nilsson, T.: GPT2: Empirical slant delay model for radio space geodetic techniques, Geophy. Res. Lett., 40, 1069-1073, doi:10.1002/grl.50288, 2013.

Letellier, T.: Etude des ondes de marée sur les plateaux continentaux, $\mathrm{PhD}$ thesis, Université de Toulouse III, Ecole Doctorale des Sciences de l'Univers, de l'Environnement et de l'Espace, 2004.

Li, X., Dick, G., Ge, M., Heise, S., Wickert, J., and Bender, M.: Real-time GPS sensing of atmospheric water vapor: Precise point positioning with orbit, clock, and phase delay corrections, Geophy. Res. Lett., 41, 3615-3621, doi:10.1002/2013GL058721, 2014.

Marengo, J. A. and Bernasconi, M.: Regional differences in aridity/drought conditions over Northeast Brazil: present state and future projections, Clim. Change, 129, 103-115, doi:10.1007/s10584-014-1310-1, 2014.

Mears, C., Wang, J., Ho, S.-P., Zhang, L., and Zhou, X.: States of the Climate in 2009, chap. Total column water vapor, 91, 29-31, B. Am. Meteorol. Soc., doi:10.1175/BAMS-91-7StateoftheClimate, 2010.

Niell, A.: Global Mapping Function for the Atmosphere Delay at radio Wavelenght, J. Geophys. Res., 101, 3227-3246, doi:10.1029/95JB03048, 1996.

Nilsson, T. and Elgered, G.: Long-term trends in the atmospheric water vapor content estimated from groundbased GPS data, J. Geophys. Res.-Atmos., 113, D19101, doi:10.1029/2008JD010110, 2008.

NIMA: Department of Defense World Geodetic System 1984, Its Definition and Relationships with Local Geodetic Systems, Tech. Rep. NIMA TR8350.2 Third Edition Amendment 1, National Imagery and Mapping Agency, 2000. 
Nott, J.: Extreme Events: A Physical Reconstruction and Risk Assessment, Cambridge University Press, ISBN-13 978-0-52182412-5, 2006.

Pavlis, N. K., Holmes, S. A., Kenyon, S. C., and Factor, J. K.: The development and evaluation of the Earth Gravitational Model 2008 (EGM2008), J. Geophys. Res.-Sol. Ea., 117, B04406, doi:10.1029/2011JB008916, available at: http://earth-info.nga.mil/GandG/wgs84/gravitymod/egm2008/ egm08_wgs84.html (last access: 6 November 2015), 2012.

Peel, M. C., Finlayson, B. L., and McMahon, T. A.: Updated world map of the Köppen-Geiger climate classification, Hydrol. Earth Syst. Sci., 11, 1633-1644, doi:10.5194/hess-11-16332007, 2007.

Petit, G. and Luzum, B.: IERS Conventions (2010), Tech. Rep. 36, IERS Conventions Centre, 2010.

Philipona, R., Dürr, B., Ohmura, A., and Ruckstuhl, C.: Anthropogenic greenhouse forcing and strong water vapor feedback increase temperature in Europe, Geophy. Res. Lett., 32, L19809, doi:10.1029/2005GL023624, 2005.

Rebischung, P.: [IGSMAIL-7055] Combined repro2 SINEX solutions available, available at: ftp://igs-rf.ensg.eu/pub/repro2 (last access: 2 January 2016), 2015.

Rebischung, P., Griffiths, J., Ray, J., Schmid, R., Collilieux, X., and Garayt, B.: IGS08: The IGS Realization of ITRF2008, GPS Solut., 16, 483-494, doi:10.1007/s10291-011-0248-2, 2012.

Ross, R. J. and Elliott, W. P.: Tropospheric Water Vapor Climatology and Trends over North America: 1973-93, J. Climate, 9, 3561-3574, doi:10.1175/15200442(1996)009<3561:TWVCAT>2.0.CO;2, 1996.

Salby, M. L.: Climate System Modelling, chap. The Atmosphere, Cambridge University Press, Cambridge, UK, 1992.

Sapucci, L. F., Machado, L. A. T., Monico, J. F. G., and PlanaFattori, A.: Intercomparison of Integrated Water Vapor Estimates from Multisensors in the Amazonian Region, J. Atmos. Ocean. Tech., 24, 1880-1894, doi:10.1175/JTECH2090.1, 2007.

Smith, A., Lott, N., and Vose, R.: The Integrated Surface Database: Recent Developments and Partnerships, B. Am. Meteorol. Soc., 92, 704-708, doi:10.1175/2011BAMS3015.1, available at: ftp://ftp.ncdc.noaa.gov/pub/data/noaa/isd-lite/ (last access: 25 November 2015), 2011.

Steigenberger, P., Tesmer, V., Krügel, M., Thaller, D., Schmid, R., Vey, S., and Rothacher, M.: Comparisons of homogeneously reprocessed GPS and VLBI long time-series of troposphere zenith delays and gradients, J. Geodyn., 81, 503-514, doi:10.1007/s00190-006-0124-y, 2007.

Steigenberger, P., Hugentobler, U., Lutz, S., and Dach, R.: CODE Contribution to the 2nd IGS Reprocessing, in: IGS Workshop 2014, Astronomisches Institut der Universität Bern, Bern, Switzerland and Technische Universitat, München, Münich, Germany, available at: http://www.bernese.unibe.ch/publist/2014/ post/CODE_repro2_IGSWS14.pdf (last access: 9 September 2015), 2014.

Systéme d'Observation du Niveau des Eaux Littorales: SONEL GNSS data set, available at: ftp://ftp.sonel.org/gps/data/, last access: 28 March 2016.
Trenberth, K., Fasullo, J., and Smith, L.: Trends and variability in column-integrated atmospheric water vapor, Clim. Dynam., 24, 741-758, doi:10.1007/s00382-005-0017-4, 2005.

Turco, R. P.: Climate System Modelling, chap. Atmospheric Chemistry, Cambridge University Press, Cambridge, UK, 1992.

University of Wyoming: Surface Observations data set, available at: http://weather.uwyo.edu/surface/meteorogram/, last access: 27 November 2015.

University of Wyoming: Upper Air data set, available at: http://weather.uwyo.edu/upperair/sounding.html, last access: 27 November 2015.

van Dam, T., Altamimi, Z., Collilieux, X., and Ray, J.: Topographically induced height errors in predicted atmospheric loading effects, J. Geophys. Res.-Sol. Ea., 115, B07415, doi:10.1029/2009JB006810, 2010.

van Dam, T. M. and Ray, R.: S1 and S2 Atmospheric Tide Loading Effects for Geodetic Applications, available at: http://geophy.uni. lu/ggfc-atmosphere/tide-loading-calculator.html (last access: 7 September 2015), 2010.

Vey, S., Dietrich, R., Fritsche, M., Rüke, A., Steigenberger, P., and Rothacher, M.: On the homogeneity and interpretation of precipitable water time series derived from global GPS observations, J. Geophys. Res.-Atmos., 114, D10101, doi:10.1029/2008JD010415, 2009.

Vey, S., Dietrich, R., Rülke, A., Fritsche, M., Steigenberger, P., and Rothacher, M.: Validation of Precipitable Water Vapor within the NCEP/DOE Reanalysis Using Global GPS Observations from One Decade, J. Climate, 23, 1675-1695, doi:10.1175/2009JCLI2787.1, 2010.

Wang, J., Zhang, L., Dai, A., Van Hove, T., and Van Baelen, J. A near-global, 2-hourly data set of atmospheric precipitable water from ground-based GPS measurements, J. Geophys. Res.Atmos., 112, D11107, doi:10.1029/2006JD007529, 2007.

Wang, X., Zhang, K., Wu, S., Fan, S., and Cheng, Y.: Water vaporweighted mean temperature and its impact on the determination of precipitable water vapor and its linear trend, J. Geophys. Res.Atmos., 121, 833-852, doi:10.1002/2015JD024181, 2016a.

Wang, Y., Zhang, Y., Fu, Y., Li, R., and Yang, Y.: A climatological comparison of column-integrated water vapor for the thirdgeneration reanalysis datasets, Sci. China Ser. D, 59, 296-306, doi:10.1007/s11430-015-5183-6, 2016b.

Ware, R. H., Fulker, D. W., Stein, S. A., Anderson, D. N., Avery, S. K., Clark, R. D., Droegenmeier, K. K., Kuettner, J. P.and Minster, J. B., and Sorooshian, S.: SuomiNet: A Real-Time National GPS Network for Atmospheric Research and Education, B. Am. Meteorol. Soc., 81, 677-694, doi:10.1175/15200477(2000)081<0677:SARNGN>2.3.CO;2, 2000.

Zdunkowski, W. and Bott, A.: Thermodynamics of the atmosphere, Cambridge University Press, Cambridge, UK, ISBN 978-0-52180953-5, 2004.

Zhai, P. and Eskridge, R. E.: Analyses of Inhomogeneities in Radiosonde Temperature and Humidity Time Series, J. Climate, 9, 884-894, doi:10.1175/15200442(1996)009<0884:AOIIRT>2.0.CO;2, 1996. 